\title{
Determinants of Sectoral Average Wage Growth Rates in a Specific Factors Model with International Capital Movements ${ }^{1}$
}

\author{
Ivo De Loo, \\ MERIT, Maastricht University \\ Thomas Ziesemer, \\ Department of Economics and MERIT, Maastricht University
}

January 1998

\begin{abstract}
The cost-minimization part of a specific factors model with perfect capital movements and both perfect and imperfect competition is used here to explain the growth rate of wages as a function of technical change, terms of trade changes, interest rate changes and the growth of the labour supply. Our estimation of the perfect competition model for 67 combinations of countries and sectors yields the result that technical change explains a higher percentage of wage growth than changes in the terms of trade do before the 1980s. From the 1980s onwards, international trade is slightly more influential than technical progress. Much more important than these two are changes in sector specific labour supply in all countries but the UK. In the UK terms of trade changes matter most. However, since we cannot exclude increasing returns, a model with imperfect competition is also estimated. Besides a confirmation of the strong results for labour, evidence of increasing returns is found in especially Germany and the US. No such evidence is found in Spain. Since firms and sectors ask governments for protectionism or for compensation for losses from trade, it seems that, given the dominance of the labour supply variable in both the perfect and the imperfect competition version of our model, it is reasonable to search for a diagnosis and a solution to trade problems in the labour market sphere.
\end{abstract}

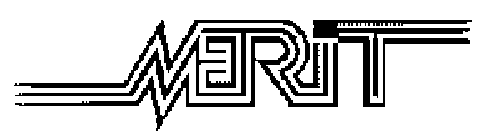

Maastricht Economic Research Institute on Innovation and Technology, University of Maastricht, P.O. Box 616, 6200 MD Maastricht, The Netherlands, tel: +31 43 3883867 / 3872, fax: +31 43 3216518, Email: i.deloo@merit.unimaas.nl and t.ziesemer@algec.unimaas.nl

1. The perfect competition part of this paper has been presented at the ESF conference 'Economic growth in closed and open economies', Lucca, September 1997, the TSER group seminar on technology and employment, Paris, October 1997 and the conference 'Unemployment in Europe', Maastricht, October 1997. We especially would like to thank Luc Soete, Huw Lloyd-Ellis, Giovanni Russo and Winfried Vogt for their comments. The usual disclaimer applies. 


\section{Introduction}

Sectoral wages are the average of the wages for skilled and unskilled labour. Explaining their development has recently led to some controversies (see Freeman 1995). The major problems discussed are why do wages for skilled and unskilled labour diverge in the US and why has unemployment been heavily concentrated on low-skilled workers in Europe? These shifts can also be observed in Newly Industrialized Countries (NICs) (see Richardson 1995). The wage determination question, however, is of broader interest.

Many economists using closed or open economy growth models would explain wage growth mainly as a consequence of technical progress. Labour market economists would tend to emphasize (sectoral) supply and demand with little weight on international aspects (see Richardson 1995). Trade economists would tend to ignore the supply of labour when using the Stolper-Samuelson theorem. However, in a multisectoral world of international trade and capital movements it is tempting to take a broader perspective. Consequently, one may ask the question what the relative importance of the major determinants of (average) wage growth and employment -international trade or factor movements, technological change or labour market developments- are once one integrates all of them into one framework. In this paper we try to answer this question with regard to the US and six European countries (where wage inequality has changed much less than in the US). The inequality issue will not be addressed in this paper. We analyze average wages.

Lawrence and Slaughter (1993) and Krugman (1994) have argued that international trade would have an impact on wages, if any, via changes in the terms of trade. However, they indicated that the terms of trade of the US are almost unchanged and therefore changes in wages must be due to technical change. This argument leaves us with several open issues:

i) Results may be different for other countries than just the US;

ii) Results may change if we do not only argue in terms of a two-sector model but at a more disaggregated level, because some of us will remember that in continental Europe the shipbuilding sector did shrink in the 1970s, automobile business was faced with increased competition from Japan in the early eighties and the European consumer electronics sector lost grounds in the 1980s and 1990s. Ultimately, protectionists lobby at the sectoral or even firm level and not at the macro level;

iii) Once international capital movements are taken into account, not only the terms of trade but also interest rates become an exogenous variable for a (model of a) country and their changes should also have an impact on wage growth according to economic theory.

How did the literature treat these three issues? The only contribution on average wages so far is Lawrence and Slaughter (1993). Some other insights are gained from the wage inequality debate by:

i) Lücke (1997), who has looked at data for Germany and the UK and Oscarsson (1997) for Sweden. Seemingly, for many other countries this has not been done within an international trade framework. Oliveira Martins (1994), using an 
industrial economics rather than an international trade approach also looks at several countries;

ii) Leamer (1996), who also sees the point of relevance for single sectors, mentioning apparel and textiles in the US. Krugman and Lawrence (1993) acknowledge that Japan did threaten US textiles in the 1960s and semiconductors in the 1990s;

iii) Leamer (1993), who takes international capital movements into account when making theoretical scenarios but not when running estimations. Wood (1994), as well as Sachs and Shatz (1994), look at several sectors and international capital movements too. However, they do not have an integrating framework but rather look at all aspects, separately running regressions that give some intuition on their idea that international trade, technology and international capital movements are all important. Thus, it seems to be worthwhile to investigate all of these points more closely.

Most of the wage inequality debate has been conducted in terms of HeckscherOhlin models (see Sachs and Shatz 1994, Baldwin and Cain 1997, Lücke 1997). Krugman and Obstfeld (1997) give a justification for this choice: although labour may not be mobile between sectors because its skills are specific to one sector only, reschooling could achieve the desired mobility after some time, which would justify the mobility assumption of the Heckscher-Ohlin model. Against this we like to propose that before reschooling, labour is specific to one (or several) sector(s) and after reschooling it is specific to different sectors or just one. We prefer to capture this with a specific factors model that has an exogenously changing labour supply for each sector and allows for sectoral differences in wages, whereas the HO model does not (see Leamer 1994). Also, most of the literature uses the Stolper-Samuelson theorem for the analysis (see Leamer 1994, Richardson 1995, Baldwin and Cain 1997, Lücke 1997), which makes the latter heavily dependent on the empirical validity of the zero-profit conditions in every sector or period ${ }^{2}$. Using the costminimization part of a specific factors model with perfect competition and international capital movements can avoid this drawback and provides a simple way to include the supply of labour, technical change, international trade and factor movements in one framework. Yet, it does so at the cost of slightly exaggerating the immobility aspect of labour (which is now restricted to just one sector). Other alternatives to the Stolper-Samuelson approach are represented in Francois (1996).

To allow for the treatment of more sectors motivated under point ii) above we will construct a multisectoral, specific factors model in section 2 . The inclusion of

2. Note that the estimation of Jones' (1970) dynamic version of the zero-profit conditions uses data on factor shares (see Baldwin and Cain 1997), which consist of a cost term in the numerator and revenue terms in the denominator. If we (empirically) have zero-profits on average across time, we might guess from a business cycle perspective that there are losses in recessions and positive profits in booms. This yields higher than average values of cost shares in recessions and lower values in booms. In time series estimates this may bias the results, in particular in view of the possibility that capital and labour shares may be affected unequally because of the irreversibility (or costly reversibility) of the investment of capital which makes it difficult to reduce its cost in a recession. 
international capital movements brings in interest rate changes in accordance with the motivation of point iii) above. In section 3, some remarks on the data and analysis techniques are made. Section 4 contains our main findings, whereafter section 5 will discuss the policy conclusions which may be drawn from them. Finally, section 6 addresses the limitations of our approach and gives some guidelines for further research.

\section{Model Description}

The details of the model are as follows. For each product $i$ we assume the following production function to be responsible for the generation of variable costs, where $Y$ indicates output, $K$ capital, $L$ labour and $A$ technology:

$$
Y^{i}=\left(K^{i}\right)^{\alpha^{i}}\left(A^{i}\right)^{\theta^{i}}\left(L^{i}\right)^{\beta^{i}}
$$

$\alpha, \beta$ and $\theta$ are elasticities of the production of capital, labour and technology. If the sum of $\alpha$ and $\beta$ is smaller, larger than or equal to one, we have decreasing, increasing or constant returns to scale and therefore upward, downward or constant sloping cost functions (for given technology $A$ ). We do not exclude any of these cases a priori.

From cost minimization we get (with $w$ as the wage rate and $r$ as the rate of interest):

$$
\begin{aligned}
w^{i} & =\lambda^{i} F_{L^{i}}^{i} \\
r & =\lambda^{i} F^{i}{ }_{K^{i}}
\end{aligned}
$$

$\lambda$ is the Lagrange multiplier of the technology constraint, whose economic interpretation is marginal costs. Lower indices $K$ or $L$ indicate a partial derivative with respect to $K$ or $L$. The three equations given above allow us to find a solution for the value of the Lagrange multiplier $\lambda$. We get:

$$
\begin{gathered}
\lambda=\left(\frac{r}{\alpha}\right)^{a} Y^{b} A^{c}\left(\frac{w}{\beta}\right)^{d} \\
\text { with } \\
a=\frac{\alpha}{\alpha+\beta}, b=\frac{1-\alpha-\beta}{\alpha+\beta}, c=\frac{-\theta}{\alpha+\beta}, d=\frac{\beta}{\alpha+\beta}
\end{gathered}
$$

In case of perfect competition marginal costs equal prices given from the world market (under the small country assumption) and marginal productivity conditions can therefore be rewritten as:

$$
\begin{gathered}
w^{i}=p^{i} F_{L^{i}}^{i} \\
r=p^{i} F^{i}{ }_{K^{i}}
\end{gathered}
$$

Rewriting the marginal productivity conditions in growth rates, using the CobbDouglas form of production functions, and the elimination of the term for capital yields an equation for several sectors in different countries (we do not write down a country index): 


$$
\begin{gathered}
\hat{w}^{i}=\gamma_{1} \hat{p}^{i}+\gamma_{2} \hat{r}+\gamma_{3} \hat{A}^{i}+\gamma_{4} \hat{L}^{i} \\
\text { with } \\
\gamma_{1}=\frac{1}{1-\alpha^{i}}, \gamma_{2}=-\frac{\alpha^{i}}{1-\alpha^{i}}, \\
\gamma_{3}=\frac{\theta^{i}}{1-\alpha^{i}}, \quad \gamma_{4}=\frac{\beta^{i}+\alpha^{i}-1}{1-\alpha^{i}}
\end{gathered}
$$

In this model, the terms of trade are exogenous in case of perfect competition and the small country assumption. These assumptions are made in most of the related literature. With perfect capital movements the real interest rate, $r$, is given from the world market at each moment in time. Technology is exogenous by assumption and so is labour input because of the assumption that it is specific to each sector. Alternatively, we could have had employment as an endogenous variable and wages as an exogenous one. Then the equation would try to explain employment of a sector in a country ${ }^{3}$.

The right side of the above equation captures all variables that play a role in the debate on real wages. International trade is captured by changes in the terms of trade, technology is contained and international capital movements are represented by changes in the interest rate. Finally, factor supply is included which could not be done in a Stolper-Samuelson approach using the zero-profit assumption.

An estimate of this equation at the firm level would give us a result for $\alpha$, the elasticity of production of capital of a sector in a country, from either $\gamma_{1}$ or $\gamma_{2}$. Therefore we have to impose or test the constraint that:

$$
\gamma_{1}+\gamma_{2}=1
$$

when doing the estimation. Having found a value for $\alpha$ we can deduct the value of $\beta$ from $\gamma_{4}$ and that of $\theta$ from $\gamma_{3}$. The question whether or not we have increasing returns to scale can be answered by looking at $\gamma_{4}$. If it is less, more than or equal to zero, we have decreasing, increasing or constant returns to scale in labour and capital. However, only if the previous coefficient restriction is accepted we may draw such a conclusion, for then we can suspect that the definitions of the other coefficients hold too. The assumption of perfect competition is only justified if we have non-increasing returns to scale. In the case of increasing returns to scale we have to resort to imperfect competition and endogenous prices and therefore we must give up the small country assumption, because price determination by domestic firms and prices given from the world market are mutually exclusive

3. In the standard partial equilibrium labour market diagram an increase in the labour supply would decrease wages. However, the increase in employment has an indirect effect via the marginal productivity of capital, which is increased by higher employment and therefore more capital is attracted. With the increase in capital, labour demand also increases which would increase wages. Under increasing (decreasing) returns to scale the indirect demand effect is stronger (weaker) than the direct supply effect. 
concepts (see Helpman and Krugman 1989). If a sector is faced with a constantelasticity demand function, $p^{i}=B^{i} Y^{i \phi} M_{e u}^{i \delta} M_{n e u}^{i \varepsilon}$, with $\phi$ as an inverse of the price elasticity, $M_{e u}$ as import quantities of competing products from the EU, $M_{n e u}$ as their non-European equivalent, $B$ as a shift parameter which captures all other demand effects (such as effects of other imports coming into the country), and each product being produced by only one firm (as it would under monopolistic competition), profit maximization will yield $p^{i}=\lambda^{i} /\left(\phi^{i}+1\right)$. Prices are now an endogenous variable because marginal costs $(\lambda)$ are endogenous for they depend on output and wages. A division between European and non-European trade is made because competition from the Asian NICs has been of special interest in the recent debate. If it has a weak (large) impact we would expect $\delta<(>) \varepsilon$.

Equating prices from the first-order conditions with those of the demand function yields:

$$
B^{i} Y^{i \phi} M_{e u}^{i \delta} M_{\text {neu }}^{i \varepsilon}=\lambda^{i} /\left(\phi^{i}+1\right)
$$

Taking growth rates of this equation, the marginal productivity conditions and the expression for $\lambda$ yield four linear equations for four endogenous variables: the growth rates of wages $(w)$, capital $(K)$, marginal costs $(\lambda)$ and output $(Y)$. The exogenous variables are the growth rates of $A, L, r, M_{e u}$ and $M_{\text {neu }}$. Parameters are $\alpha, \beta, \theta, a, b, c, d, \delta, \varepsilon$ and $\phi$.

Solving the system for the growth rate of wages yields:

$$
\begin{gathered}
\hat{w}^{i}=e_{0}+e_{2} \hat{r}+e_{1 a} \hat{M}_{e u}^{i}+e_{1 b} \hat{M}_{n e u}^{i}+e_{3} \hat{A}^{i}+e_{4} \hat{L}^{i} \\
\text { with } \\
e_{0}=\frac{-\hat{B}}{\alpha(\phi+1)-1}, e_{2}=\frac{\alpha(\phi+1)}{\alpha(\phi+1)-1}, \\
e_{1 a}=\frac{-\delta}{\alpha(\phi+1)-1}, e_{1 b}=\frac{-\varepsilon}{\alpha(\phi+1)-1}, \\
e_{3}=\frac{\frac{\phi(\beta-\theta)}{1-\alpha-\beta}-\beta(\phi+1)}{\alpha(\phi+1)-1}, e_{4}=-1-\frac{\beta(\phi+1)}{\alpha(\phi+1)-1}
\end{gathered}
$$

In this equation, compared to that of the perfect competition case, imports are the exogenous variable that replace prices. As the exogenous shift variable $B$ can go either way, but probably is decreasing because of the rise of the NICs, competition is increased. Therefore, the demand function is shifted towards lower prices.

Once we have estimated $e_{0-4}$, we can successively infer values of $\alpha(\phi+1)$ from $e_{2}, \beta(\phi+1)$ from $e_{4}$ and $\frac{\phi(\beta-\theta)}{1-\alpha-\beta}$ from $e_{3}$. Furthermore, we can obtain the value of 
$\delta$ from $e_{1 a}$, that of $\varepsilon$ from $e_{1 b}$, and the growth rate of $B$ from $e_{0}^{4}$. Then, we do not get to know the sum $(\alpha+\beta)$ and whether or not a sector has increasing returns to scale. Nevertheless, we can derive the following (sufficient) condition which, if it is found to be larger than one, may indicate increasing returns ${ }^{5}$ :

$$
\alpha(\phi+1)+\beta(\phi+1)=\phi(\alpha+\beta)+(\alpha+\beta)>1 \Rightarrow I R S
$$

Moreover, we cannot see whether or not the price elasticity is in the (elastic) range $0>\phi>-1$. What we can see, is whether $\delta, \varepsilon<0$ and $\alpha(\phi+1), \beta(\phi+1)>0$ (if all the coefficient definitions hold). The restrictions follow from the requirement of positive values for the elasticity of production and the requirement that the inverse price elasticity should lie between zero and minus one.

\section{Data and Econometric Methods}

The estimated equations have been derived from the firms' rules for cost minimization and profit maximization. Unfortunately, we do not have data on the firm or product level. Therefore, we performed the estimation at the sectoral level. Aggregating the left and right hand sides of the equation across products to generate a sectoral equation is possible without problems only if all products have the same values for all the parameters or have the same growth rate of prices. We are not aware of any solution to this aggregation problem. Assuming that a similar equation holds for sectors may not be too heroic. However, it is anything but clear that the parameter constraints are still reasonable. We will therefore estimate the equations both with and without them.

Having constructed a model that is very similar to those of standard international trade models in textbooks we have to relate a non-monetary model to data which stem from a monetary world. This requires to divide the data for wages and sectoral prices by the GDP price level of the country in question. Moreover, nominal interest rates have to be deflated by subtraction of the growth rate of the GDP deflator. We start from national nominal interest rates, because in spite of our assumptions it is not clear that national capital markets are perfect. Although we have not modelled capital market imperfections explicitly, national rates seem to be the more adequate data.

We will test for structural breaks. The question whether employment drives wages or wages drive employment will be 'answered' using Granger causality.

4. Theoretically, this is indeed possible. In practice, since we will be solving a system of six highly non-linear equations, there is no guarantee that either any or just one solution exists.

5. Provided that $\phi$ is negative and $\alpha, \beta>0$. 
The regression equation will be estimated by $\mathrm{OLS}^{6}$ without the aforementioned coefficient restrictions (at least initially). This technique is applied so that a heteroscedasticity-consistent covariance matrix arises ${ }^{7}$. At first, a constant term is included in the regressions to capture the mean effect of (possibly) missing variables (like additional productive factors). We expect $\gamma_{1}$ and $\gamma_{3}$ to have a positive sign, $\gamma_{2}$ to have a negative one, whereas $\gamma_{4}$ and $\gamma_{0}$ (which will still be used to denote the constant term) can have either sign. A description of the data can be found in appendix A1. At this point, only the choice of R\&D expenditures as a proxy of technical change will be elaborated upon.

Basically, there are two sets of indicators that can serve as a proxy of technical change: $R \& D$ data and patent statistics. However, both have their drawbacks. R\&D data are an input measure of the innovation process. Not all R\&D inputs lead to innovations, and also the efficiency with which inputs are used influences the amount of successful R\&D efforts. Thus, more $R \& D$ expenditures do not necessarily imply more innovative activities. On the other hand, patent statistics are an output measure of the innovation process. Not all innovations are patented, and not all patents are put to effective and/or commercial use ${ }^{8}$. Moreover, the propensity to patent differs between countries ${ }^{9}$. In addition, neither R\&D expenditure data nor patent data refer exclusively to process innovation as our model does. At least product innovations for consumers should be excluded (but cannot). Nevertheless, the decision to use R\&D expenditures as a proxy of technical change was mainly motivated by data availability, which was larger for R\&D data.

\section{Results and Interpretations}

In section 4.1 we will discuss the estimation results for the perfect competition model, whereafter in section 4.2 the results for the imperfect competition model are examined.

6. Applying NLS or ML (while simultaneously imposing the coefficient restriction derived in the theoretical part) would have been an option, were it not that we would then be implying that the coefficient restriction already holds a priori. OLS thus seems to be preferable. Pooling data (across sectors, countries or both) would have been an option too, but it was dropped when relatively little interpretable results emerged. See also footnote 18 and 37.

7. White's method (1980) is used to achieve this.

8. Scherer (1983) and Griliches (1990) examine the points in favour and against using either R\&D or patent statistics as an indicator of technical change more closely.

9. Cf. Scherer (1983) and Feldman and Florida (1994). See Caniëls (1997) for European evidence hereof. 


\subsection{The Case of Perfect Competition}

The basic regression output is shown in appendix $\mathrm{B} 1{ }^{10}$. As can be seen, the constant term is (statistically) significant at the 5\% level for entire Germany, almost all of Italy (except for textiles, footwear and leather products and the basic metals sector), whereas it is only significant for the French fabricated metal products industry, the French, British and Spanish paper and printing industry and the Spanish chemical industry. For the Netherlands and the US, a rather mixed picture emerges (with chemicals, total manufacturing, stone, clay and glass and paper and printing being the significant sectors for the Netherlands and chemicals, leather products, food, drink and tobacco, total manufacturing and other manufacturing industries for the US). Reasons for this outcome may be that labour market aspects (like changes in union power, falling real values of the minimum wage, an upgrading of skills and compensation policies of firms), incomplete capacity utilization, developments in the non-traded sector, or additional production factors (like land and natural resources) are at work (which are all not present in our model).

Most of the other variables do have the expected signs to some degree, but are often not significant, as is typical of the whole literature discussed above. An exception is the labour variable, which is generally both positive and significant (only the British food, drink and tobacco and other manufacturing industries have a negative coefficient). This might point to increasing returns. In a situation of perfect competition (as we have here), it would be inconsistent with our approach for it implies the possibility of ever increasing profits. However, it is far from clear that this is indeed the case because we will show below that we have an aggregation problem in the empirical part (which we already indicated in the theoretical part above $)^{11}$.

It is likely that there are structural breaks underlying the results. Such breaks may especially stem from the movement from negative to positive real interest rates at the beginning of the 1980s. For Great-Britain, Germany, Italy and the Netherlands, such a change in sign occurs in 1981. In France it occurs in 1980, whereas in Spain and the US, a change in sign of the real interest rate takes place in 1976 and 1986 respectively. Moreover, the dollar crash of 1985 may have induced another structural break. To test for these notions, a Chow break test ${ }^{12}$ is applied to both

10. Three sectors were excluded because of missing $R \& D$ data: the Dutch and Italian wood, cork and furniture sector and the Dutch other manufacturing industry.

11. An alternative interpretation that is somewhat independent of our model could be that the economy is moving along the labour supply curve - a view often found in the work of Bovenberg (see Bovenberg 1995 for details).

12. See Chow (1960) for details. 
the aforementioned year of the sign change in the real interest rate and the dollar $\operatorname{crash}^{13}$. The results hereof are also given in appendix B1.

If we refrain from the outcome for total manufacturing ${ }^{14}$, only a limited number of breaks is found. They arise for the French and British stone, clay and glass industry, the French chemical, fabricated metal products, food, drink and tobacco and wood, cork and furniture industries and the German and Italian other manufacturing industry. Also, a structural break occurs for the German fabricated metal products. The British stone, clay and glass sector solely seems to have been affected by the dollar crisis of the mid 1980s. Therefore, it is decided to let the estimation period for these sectors begin at either 1980, 1981 or 1986 instead of (mostly) 1974 and to redo the estimation. The results of this estimation process (taking into account structural breaks) are depicted in appendix B2 ${ }^{15}$.

Although there are changes to be seen (for example, a wrong change in sign for the price variable of the German fabricated metal products sector and a correct one for the technology variable of the corresponding French industry, and a drop in significance (and magnitude) of the labour variable of the French paper and printing industry), the overall results are not very different from those of appendix B1. Thus, structural breaks do not seem to be at the heart of the unexpected signs and large sizes of some of the variables in our model. Factors that remain are the significance of the constant term (in some equations) and the fact that we have not yet imposed the coefficient restriction derived in the theoretical part. If we leave out the constant term for those sectors for which it is statistically insignificant at the 5\% level and then test whether the proposed restriction is in place, we obtain the results of appendix $\mathrm{B} 3{ }^{16}$.

13. It is reckoned that econometrically more sophisticated methods exist to assess points in time at which structural breaks occur (see for example Gallant and Fuller 1973). However, we believe that it is better to follow economic reality to pinpoint years of structural breaks than an econometric method.

14. Where structural breaks are detected in the early 1980s for Germany and France and in the late 1980s for Spain.

15. From a model point of view, the period characterized by positive real interest rates is the only one of interest, because only then the model holds. It is assumed however that when no structural breaks are found, the influence of negative real interest rates on the regression results is negligibly small.

16. All regressions were also carried out with a time variable included. This variable was always insignificantly different from zero at a 5\% significance level (which is not that surprising, since we are working with series expressed in first differences). 
The omission of the constant term alters our results somewhat (leading, among others, to both smaller (yet more significant) values of the labour variable) ${ }^{17}$, but the overall results are quite similar to the ones already reached in appendix B2. Besides, we see that at the 5\% significance level, the coefficient restriction can be accepted only 7 times. We find significant results for the French food, drink and tobacco, basic metals and other manufacturing industries, the British leather products and other manufacturing industries and the Dutch fabricated metal products and stone, clay and glass industries. Only for these sectors we may, if we get plausible estimates for $\alpha$ and $\beta$, say something about the presence of increasing returns. It is unlikely that plausible estimates arise for all seven sectors, because for only three of them all coefficients have the required signs: basic metals in France, other manufacturing industries in the UK and fabricated metal products in the Netherlands. Besides, the $\bar{R}^{2}$ is below 0.60 in all but two cases (the two Dutch sectors). In fact, inferring values for $\alpha, \beta$ and $\theta$ does not lead to plausible estimates for any sector ( $\alpha$ lies between -.092 and $-9.23, \beta$ between 1.12 and 12.7 and $\theta$ between -.187 and .160$)^{18}$. Together with the theoretical part this indicates the presence of an aggregation problem (or omitted variables).

Of all variables, labour is for a large part significantly different from zero, whereas especially for the price and technology variables, there are many unexpected entries as far as sign and significance are concerned. However, statements about increasing or decreasing returns to scale cannot be made anymore since the restriction that would give rise to such an outcome is not accepted (and in the cases where it is, unrealistic estimates follow). It can only be said that a significant and mostly positive relationship exists between sectoral wage growth and employment growth in almost all sectors and countries under consideration ${ }^{19}$. One might suggest that specific factors matter, although the less plausible results for the other variables possibly overstates the importance of such a conclusion.

The question remains in what direction the relationship between employment and wages holds. Do wages determine employment or does employment determine

17 . Perhaps the most striking results are found for the technology variable, which now becomes both more significant and has the desired sign more often. This might point to the fact that R\&D expenditures are rather flawed an indicator of technical change. However, putting the technology variable into the residual would then again seem too drastic an action for it would, in a statistical sense, lead to omitted variable bias.

18. If all coefficient definitions given in the theoretical part are substituted into the regression equation and the model is re-estimated by means of NLS, these $\alpha, \beta$ and $\theta$ estimates follow. Of course, it would have been preferable to solve the system numerically. This did not yield any result, for then it is implicitly assumed that the imposed coefficient restriction holds exactly, whereas our test examines whether it holds within a certain margin.

19. Exceptions (with respect to significance) are the French and Dutch food, drink and tobacco sector, the French and British other manufacturing industries, and the British chemical, fabricated metal products, basic metals and stone, clay and glass industries. 
wages instead? Tentatively, this question will be 'answered' by means of Granger causality tests.

Granger causality tests ${ }^{20}$ examine whether the occurrence of a certain event (variable) $X$ precedes the occurrence of another event (variable) $Y$ over a certain period of time. Stated differently, it is tested whether variable $Y$ is temporally dependent upon variable $X$. Thus, it is not causality in a strict sense that is analyzed here: it is the order in which events happen that matters ${ }^{21}$. Besides, Granger causality is like a two-way street: only when $X$ Granger causes $Y$, and $Y$ does not (at the same time) Granger cause $X$, we may say that there is temporal dependence of $Y$ upon $X$. More specifically, the following model is estimated:

$$
Y_{t}=\delta_{0}+\sum_{p} \alpha_{p} Y_{t-p}+\sum_{q} \beta_{q} X_{t-q}+\varepsilon_{t},
$$

where $p, q=$ predetermined lag orders,

$\varepsilon_{t}=$ random disturbance term.

The null hypothesis that $X$ does not Granger cause $Y$ is that $\beta_{q}=0 \forall q$ (while simultaneously, $Y$ should not Granger cause $X$ : $\alpha_{p}=0 \forall p$ ). The size of $p$ and $q$ is mostly agreed upon a priori on theoretical grounds. Here, we will assume, letting $Y_{t}$ denote sectoral wage growth and $X_{t}$ the corresponding growth of labour, that $p$ and $q$ range from one to three. Tests were carried out with both one and two lags, but this did not alter our basic results very much. Results are presented in appendix B4.

Employment Granger causes wage growth in a limited number of cases: only for the British fabricated metal products and the food, drink and tobacco sector significant results are found (at a 5\% level of significance). However, wages determine employment growth more often: for three British sectors (chemicals, textiles, footwear and leather products and basic metals) this turns out to be the case. Two other significant results emerge, namely for Spanish leather products and the Italian paper and printing industry. For wood, cork and furniture in Germany and total manufacturing in Britain, there are statistically significant relationships in both directions: wages determine employment and by the same token, employment determines wages. Nevertheless, the conclusion in these cases is the same as for all sectors not mentioned: the Granger causality test is inconclusive.

It is quite interesting that when significant results are found, they occur most often for Great-Britain. There seems to be no apparent reason for this outcome though.

In the 5 cases where wages Granger cause employment growth, the estimation is redone, with wage growth now being an explanatory variable and labour growth the

20 . First introduced by Granger (1969). Sims (1972) and others provided tests (mostly) along the same lines, but the Granger causality test is the one most commonly used.

21. See Eels (1991) for a more elaborate analysis hereof. 
dependent one. As far as the value of the coefficients is concerned, this simply means rewriting the equations already shown in appendix B $3^{22}$. However, the fit does change, as does the significance of the coefficients. Tests for structural breaks have to be redone too. Also, in the first stage, a constant term is included in the regression equation. For the sectors for which it does not differ significantly from zero at the $5 \%$ level of significance ${ }^{23}$, it is dropped and the modified model is reestimated. These 'final' regressions are given in appendix B4.

Note that the desired sign of the explanatory variables switches when moving from wage growth to labour growth as the dependent variable. Only for the relationship between wages and labour it remains the same. Even then, there are many wrong signs to be found ${ }^{24}$. The price and interest variables have the correct sign for all five sectors. The technology variable has the wrong sign for three sectors: the British chemical and textiles, footwear and leather products industries and the Spanish leather products industry. Thus there are two sectors for which all variables have the desired sign: basic metals in the UK and paper and printing in Italy. Nevertheless, no new insights on coefficients are created here either because only the labour variable and the constant term (for basic metals in the UK) differ substantially from zero.

For those sectors where all coefficients have the expected $\operatorname{sign}^{25}$, it might be illuminating to examine how far the explanatory variables attribute to the explanation (of variation in) the dependent variable ${ }^{26}$. This means conducting a sort of 'growth accounting' exercise. From appendix B3 we see that there are many sectors for which we found the expected signs (to be specific, 27 out of 67). These sectors are shown in table 4.1 below.

22. Note that it is not necessary to test the validity of the derived coefficient restriction again because of the same reason (as long as the estimation period remains the same).

23. As turned out to be the case for the British and Spanish textiles, footwear and leather products and the Italian paper and printing industry.

24. Which is not surprising since coefficients that already had the wrong sign when wages were taken as the dependent variable, will have so now too (as long as the constant term remains either absent or present).

25. We will only look at cases where employment determines wage growth, because in the reverse situation just two sectors had all the desired signs. If we had reversed the position of the wage and labour variable in the regression equation and redone the entire analysis up to this point, we would have ended up with 13 sectors to work with (instead of the 27 we have now).

26. Ideally, we would have preferred looking at variables that have both the expected sign and are statistically significant. However, this is not the case for any sector. Since we do want to give an indication whether either terms of trade or technology drives wage growth most, the present approach is opted for. 
Table 4.1 Sectors with correct expected signs.

\begin{tabular}{||ll||}
\hline Country & Sector \\
& \\
USA & Chemicals \\
& Basic metals \\
& Paper and printing \\
France & Wood, cork and furniture \\
& Basic metals \\
& Paper and printing \\
Germany & Wood, cork and furniture \\
& Chemicals \\
Great-Britain & Paper and printing \\
& Stone, clay and glass \\
The Netherlands & Paper and printing \\
& Wood, cork and furniture \\
Spain & Other manufacturing industries \\
& Fabricated metal products, machinery and equipment \\
& Basic metals \\
Italy & Total manufacturing \\
& Food, drink and tobacco \\
& Basic metals \\
& Stone, clay and glass \\
& Wood, cork and furniture \\
& Other manufacturing industries \\
& Total manufacturing \\
& Chemicals \\
& Fabricated metal products, machinery and equipment \\
& Textiles, footwear and leather \\
Basic metals & Total manufacturing \\
\hline & \\
\hline
\end{tabular}

It is interesting to see that most sectors satisfying the correct sign assumption are the traditional ones: basic metals, paper and printing, stone, clay and glass and wood, cork and furniture.

The basic procedure we follow is to take the regression coefficients of appendix B3 and to pre-multiply them by the means of the corresponding explanatory variables (calculated as an average of the entire estimation period) ${ }^{27}$. Then, this figure is divided by the mean of the dependent variable over the same period and multiplied by 100 to arrive at percentages. Finally, to obtain country figures, unweighted means of these percentages are taken for all sectors in table 4.1 within a certain country.

27. Alternatively, we could have taken medians or calculated an average based on just the first and last period. However, given the way in which the OLS estimates are obtained, calculating means over the entire estimation period is to be preferred. 
If we leave out total manufacturing ${ }^{28}$, and check the relative importance of all variables in explaining wage growth in a certain country in the way described above, we reach the results presented in table 4.2.

Table 4.2 Relative importance of explanatory variables in explaining per country wage growth (in percentages) ${ }^{29}$.

\begin{tabular}{||lllllll||}
\hline VARIABLE & Constant $(\%)$ & $\begin{array}{l}\text { Technology } \\
(\%)\end{array}$ & Capital $(\%)$ & Trade (\%) & Labour (\%) & Residual (\%) \\
COUNTRY & & & & & & \\
USA & 14.5 & 8.3 & 1.2 & -3.0 & 55.1 & 23.8 \\
France & 0.0 & -13.9 & -23.7 & 4.5 & 155.4 & -22.2 \\
Germany & 908.3 & 61.4 & 5.2 & -9.9 & -865.0 & 0.0 \\
Great-Britain & 63.7 & -0.5 & 0.1 & 47.6 & 12.6 & -23.5 \\
Netherlands & 0.0 & -131.4 & -47.9 & -8.7 & 768.6 & -480.6 \\
Spain & 0.0 & 58.6 & 42.7 & -22.9 & -66.5 & 88.1 \\
Italy & 113.1 & 0.3 & -10.5 & 21.2 & 224.8 & -248.8 \\
\hline
\end{tabular}

Perhaps the first impression table 4.2 gives rise to, is that large parts of the explanation of wage growth are attributed to both the constant term and the residual. This implies that a significant part of wage behaviour is not captured by our model as discussed above ${ }^{30}$.

However, it does not mean that we cannot draw any conclusion from the table (at least, preliminary). It is evident that for most countries, a large part of wage growth is determined by employment growth: labour supply is a dominating factor in 6 countries (all but the UK). In the UK a substantial part is contributed by terms of trade changes ${ }^{31}$. In Italy and the UK the terms of trade are more influential than technology. Looking at the overall results, we may conclude, following Krugman and Lawrence's line of reasoning (Krugman and Lawrence 1993), that technology is a more important factor than trade in determining (national) wages in 5 countries.

28. For it is an aggregate across all other sectors, and including it would create a bias.

29. In regressions without a constant term, the residuals do not necessarily have to sum to zero. Therefore, in these cases, a certain weight is assigned to them.

30. Which was to be expected, given our previous results.

31. Leaving aside the constant term. 
Labour supply is an even more important factor. Again, specific factors seem to matter. This raises the question what we can see at the sectoral level ${ }^{32}$.

We can derive from table $4.3 \mathrm{a}$ below ${ }^{33}$ for the whole period under consideration (and from table 4.3b for the 1980s onwards -the results of which we will indicate between brackets-) that 19 (20) out of the 27 sectors included in the 'growth accounting' exercise have negative terms of trade growth, indicating that there may be an international problem. In 11 (15) sectors we have falling and in 16 (12) we have increasing wages (according to the last column). In only 5 (6) sectors R\&D expenditures have a negative growth rate. $R \& D$ therefore has a positive effect on wages, which is slightly weaker in the more recent period. Interest rates have fallen in all but 3 (9) sectors (where we considered a different time period for 2 (7) sectors) and therefore have increased wage growth (but less so in the later period). With 5 (8) exceptions labour supply has fallen and therefore -given the positive sign of the correlation- decreased wage growth. The more recent period is obviously less favourable as far as the growth rates of the terms of trade, wages, R\&D, and to a lesser extent interest rates and labour supply are concerned ${ }^{34}$.

\footnotetext{
32. A similar exercise was carried out for the period starting (mostly) from 1980 or 1981 onwards. There, we looked at sectors which had (by and large) falling growth rates of wages. With the same regression coefficients (which, in a rough sense, is a valid approach, for structural breaks have already been taken into account), we found results that were very similar to the ones obtained in table 4.2. Only for Italy substantially better results emerged: with only $22 \%$ of explained variance being attributed to the residual, labour still turned out to be the most influential factor in national wage formation, but to a drastically lesser extent (approximately 55\%). On the other hand, significantly worse results were found for Germany (where the residual explained almost $118 \%$ of wage growth). Results at the sectoral level are discussed (and shown) later on.
}

33. Of course, the same data can also be found in appendix A2.

34 . In 9 (15) cases, the growth rates of $L$ and $w$ have opposite signs, but have positive regression coefficients. The inclusion of other explanatory variables and interaction effects between them play an important role in this 'switch' in sign. 
Table 4.3a Growth rates of explanatory and dependent variables over the estimation period given by SMPL.

\begin{tabular}{|c|c|c|c|c|c|c|}
\hline Sector $^{35}$ & SMPL & Technology & Capital & Trade & Labour & Wages \\
\hline USAZMB & $74-93$ & -0.0049 & -0.0012 & 0.0015 & -0.0286 & -0.0222 \\
\hline USAZOP & $74-93$ & 0.0522 & -0.0012 & 0.0052 & 0.0108 & 0.0179 \\
\hline USAZOW & $74-93$ & 0.0209 & -0.0012 & -0.0056 & 0.0000 & 0.0046 \\
\hline USAZ35 & $74-93$ & 0.0455 & -0.0012 & -0.0019 & 0.0063 & 0.0179 \\
\hline FRAZOG & $80-91$ & 0.0234 & -0.0052 & -0.0023 & -0.0279 & -0.0129 \\
\hline FRAZOW & $80-91$ & 0.0779 & -0.0052 & -0.0051 & -0.0235 & -0.0082 \\
\hline FRAZMB & $74-91$ & 0.0791 & -0.0034 & -0.0196 & -0.0257 & -0.0219 \\
\hline DEUZ35 & $74-92$ & 0.0308 & -0.0003 & 0.0026 & 0.0034 & 0.0248 \\
\hline DEUZOG & $74-92$ & 0.0684 & -0.0003 & -0.0064 & -0.0178 & 0.0009 \\
\hline DEUZOP & $74-92$ & 0.0789 & -0.0003 & 0.0025 & -0.0031 & 0.0153 \\
\hline GBRZOO & $74-92$ & -0.0019 & -0.0001 & 0.0359 & -0.0253 & 0.0209 \\
\hline GBRZOW & $74-92$ & -0.0019 & -0.0001 & -0.0007 & -0.0152 & -0.0077 \\
\hline GBRZOP & $74-92$ & -0.0022 & -0.0001 & 0.0060 & -0.0101 & 0.0107 \\
\hline NLDZ38 & $81-93$ & 0.0190 & 0.0003 & 0.0007 & -0.0098 & -0.0007 \\
\hline NLDZMB & $74-93$ & 0.0234 & -0.0028 & -0.0083 & -0.0139 & -0.0015 \\
\hline NLDZMT & $74-93$ & 0.0187 & -0.0028 & -0.0095 & -0.0123 & 0.0028 \\
\hline ESPZLF & $80-91$ & 0.1110 & -0.0064 & -0.0188 & -0.0085 & 0.0092 \\
\hline ESPZMB & $80-91$ & 0.0173 & -0.0064 & -0.0339 & -0.0399 & -0.0323 \\
\hline ESPZOG & $80-91$ & 0.0470 & -0.0064 & 0.0005 & -0.0221 & -0.0159 \\
\hline ESPZOO & $80-91$ & 0.5407 & -0.0064 & -0.0489 & -0.0129 & 0.0017 \\
\hline ESPZOW & $80-91$ & 0.5935 & -0.0047 & -0.0189 & -0.0173 & 0.1085 \\
\hline ESPZMT & $86-91$ & 0.1177 & 0.0013 & -0.0227 & 0.0172 & 0.0128 \\
\hline ITAZLX & $74-94$ & -0.0134 & 0.1614 & -0.0057 & -0.0100 & -0.0139 \\
\hline ITAZMB & $74-94$ & 0.0847 & -0.0057 & -0.0176 & -0.0234 & -0.0104 \\
\hline ITAZ35 & $74-94$ & 0.0409 & -0.0057 & -0.0488 & -0.0046 & 0.0113 \\
\hline ITAZ38 & 74-94 & 0.0521 & -0.0057 & -0.0181 & -0.0092 & 0.0101 \\
\hline ITAZMT & 74-94 & 0.0468 & -0.0057 & -0.0193 & -0.0108 & 0.0068 \\
\hline
\end{tabular}

35. See appendix A1 for the abbreviations used. 
Table 4.3b Growth rates of explanatory and dependent variables over the estimation period given by SMPL - from the 1980s onwards.

\begin{tabular}{|c|c|c|c|c|c|c|}
\hline SECTOR & SMPL & Technology & Capital & Trade & Labour & Wages \\
\hline USAZMB & $80-93$ & -0.0257 & -0.0020 & -0.0236 & -0.0411 & -0.0405 \\
\hline USAZOP & $81-93$ & 0.05000 & -0.0014 & 0.0084 & 0.0108 & 0.0214 \\
\hline USAZOW & $81-93$ & 0.0179 & -0.0014 & -0.0023 & 0.0052 & 0.00910 \\
\hline USAZ35 & $81-93$ & 0.0508 & -0.0014 & -0.0153 & 0.0037 & 0.0143 \\
\hline FRAZOG & $80-91$ & 0.0234 & -0.0052 & -0.0023 & -0.0279 & -0.0129 \\
\hline FRAZOW & $80-91$ & 0.0779 & -0.0052 & -0.0051 & -0.0235 & -0.0082 \\
\hline FRAZMB & $83-91$ & 0.0362 & -0.0020 & -0.0155 & -0.0310 & -0.0358 \\
\hline DEUZ35 & $81-91$ & 0.0197 & $2.21 \mathrm{e}-04$ & 0.0066 & 0.0070 & 0.0206 \\
\hline DEUZOG & $81-91$ & 0.0171 & $2.21 \mathrm{e}-04$ & $-9.84 \mathrm{e}-04$ & -0.0138 & -0.0016 \\
\hline DEUZOP & $81-91$ & -0.0068 & $2.21 \mathrm{e}-04$ & -0.0016 & 0.0085 & 0.0192 \\
\hline GBRZOO & $81-92$ & -0.0646 & -0.0087 & 0.0546 & -0.0285 & 0.0417 \\
\hline GBRZOW & $81-92$ & -0.0020 & -0.0087 & -0.0034 & -0.0099 & -0.0036 \\
\hline GBRZOP & $81-92$ & -0.0018 & -0.0087 & 0.0034 & -0.0138 & 0.0154 \\
\hline NLDZ38 & $81-93$ & 0.0190 & $3.34 \mathrm{e}-04$ & $6.69 \mathrm{e}-04$ & -0.0098 & $-7.45 e-04$ \\
\hline NLDZMB & $81-93$ & 0.0398 & $3.34 \mathrm{e}-04$ & $9.58 \mathrm{e}-04$ & -0.0153 & -0.0061 \\
\hline NLDZMT & $81-93$ & 0.0209 & $3.34 \mathrm{e}-04$ & 0.0030 & -0.0072 & 0.0034 \\
\hline ESPZLF & $86-91$ & 0.0666 & 0.0013 & -0.0203 & 0.0144 & 0.0152 \\
\hline ESPZMB & $81-91$ & 0.0116 & -0.0026 & -0.0367 & -0.0450 & -0.0410 \\
\hline ESPZOG & $81-91$ & 0.0341 & -0.0026 & -0.0087 & -0.0219 & -0.0200 \\
\hline ESPZOO & $86-91$ & 0.7448 & 0.0013 & -0.0612 & 0.0103 & 0.0184 \\
\hline ESPZOW & $81-91$ & 0.6157 & -0.0026 & -0.0124 & -0.0182 & -0.0265 \\
\hline ESPZMT & $86-91$ & 0.1177 & 0.0013 & -0.0227 & 0.0172 & 0.0128 \\
\hline ITAZLX & $80-94$ & 0.2605 & -0.0059 & -0.0201 & -0.0181 & -0.0142 \\
\hline ITAZMB & 80-94 & -0.0015 & -0.0059 & -0.0421 & -0.0391 & -0.0270 \\
\hline ITAZ35 & $81-94$ & 0.0326 & -0.0081 & -0.0368 & -0.0102 & 0.0052 \\
\hline ITAZ38 & $81-94$ & 0.0600 & -0.0081 & -0.0245 & -0.0250 & -0.0100 \\
\hline ITAZMT & 80-94 & 0.0498 & -0.0059 & -0.0224 & -0.0192 & -0.0076 \\
\hline
\end{tabular}

From table 4.4a below (and table 4.4b for the more recent period of the 1980s the results of which are again given between brackets-), containing a similar table as table 4.2, but then at the sectoral level, it follows that in 11 (16) out of the 27 sectors terms of trade have a larger impact than technology. This means that technology matters more often over the whole period but terms of trade changes are 
more influential in the recent period. Out of these 11 (16) sectors, 8 (10) have falling terms of trade. Thus at the sectoral level international trade is quite important. These 8 sectors are all but two (namely, French stone, clay and glass and British wood, cork and furniture) located in Italy and Spain. In the 1980s more sectors of these countries have terms of trade losses but also one sector in the US (basic metals) and in Germany (paper and printing). However, only 4 (9) of them have falling wages ${ }^{36}$. Again the more recent period is much less favourable (in terms of losses) than the whole period and the terms of trade have overtaken technology in importance.

In 22 (26) of the 27 national sectors labour has the strongest impact; in only 3 (0) cases it is technology and in only 2 (1) it is trade. In the more recent period labour has become even more important than it already was over the entire period. When counting variables that rank second we find 11 (11) times technology, 8 (13) times trade, 3 (0) times labour and 5 (3) times capital movements by interest changes. The overall impression therefore is that labour supply matters most, technology second, trade third and interest rates last but in the more recent period terms of trade changes take over the second position from technology. All evaluations have been made without taking the constant term or the residual into account.

36. This conclusion is independent of the fact that, for some sectors (for example leather products in Italy) a large part of wage growth is explained by the residual. Even if we had included a constant term in the regressions for these sectors anyway (and checked whether all variables had the correct signs), the economic interpretation of the results would have remained virtually the same. 
Table 4.4a Relative importance of dependent and explanatory variables in explaining per sector wage growth (in percentages).

\begin{tabular}{|c|c|c|c|c|c|c|}
\hline Sector & $\begin{array}{l}\text { Constant } \\
(\%)\end{array}$ & $\begin{array}{l}\text { Technology } \\
(\%)\end{array}$ & Capital (\%) & Trade (\%) & Labour (\%) & Residual (\%) \\
\hline USAZMB & 0.0 & 0.8 & -0.8 & -0.6 & 128.0 & -27.5 \\
\hline USAZOP & 0.0 & 4.2 & 2.0 & 3.8 & 63.6 & 26.4 \\
\hline USAZOW & 0.0 & 16.0 & 2.6 & -14.6 & -0.5 & 96.5 \\
\hline USAZ35 & 58.0 & 12.2 & 1.1 & -0.6 & 29.3 & 0.0 \\
\hline FRAZOG & 0.0 & -0.3 & -27.6 & 2.8 & 137.3 & -12.2 \\
\hline FRAZOW & 0.0 & -26.7 & -43.1 & 4.0 & 216.6 & -50.9 \\
\hline FRAZMB & 0.0 & -14.7 & -0.5 & 6.6 & 112.2 & -3.6 \\
\hline DEUZ35 & 69.3 & 17.9 & 0.9 & 1.6 & 10.3 & 0.0 \\
\hline DEUZOG & 2543.4 & 164.0 & 14.3 & -33.1 & -2588.6 & 0.0 \\
\hline DEUZOP & 112.1 & 2.3 & 0.5 & 1.8 & -16.8 & 0.0 \\
\hline GBRZOO & 0.0 & -0.8 & 0.0 & 117.7 & 8.3 & -25.2 \\
\hline GBRZOW & 0.0 & 1.4 & 0.0 & 1.7 & 142.3 & -45.4 \\
\hline GBRZOP & 191.2 & -1.9 & 0.3 & 23.4 & -113.0 & 0.0 \\
\hline NLDZ38 & 0.0 & -11.6 & 8.3 & -64.8 & 980.6 & -812.5 \\
\hline NLDZMB & 0.0 & -251.2 & -104.1 & 47.4 & 556.6 & -148.7 \\
\hline NLDZMT & 418.6 & 48.1 & 42.2 & -42.7 & -366.2 & 0.0 \\
\hline ESPZLF & 0.0 & 98.2 & 60.1 & -4.6 & -54.4 & 0.6 \\
\hline ESPZMB & 0.0 & -1.3 & -6.8 & 3.1 & 110.7 & -5.7 \\
\hline ESPZOG & 0.0 & -6.4 & -9.8 & -0.7 & 113.1 & 3.9 \\
\hline ESPZOO & 0.0 & 218.2 & 183.8 & -117.6 & -600.1 & 415.7 \\
\hline ESPZOW & 0.0 & -15.7 & -14.0 & 5.2 & 98.4 & 26.1 \\
\hline ESPZMT & 0.0 & 14.4 & -1.3 & -28.5 & 121.9 & -6.5 \\
\hline ITAZLX & 0.0 & -1.1 & -81.7 & 231.1 & 888.1 & -936.4 \\
\hline ITAZMB & 0.0 & -12.2 & -9.4 & 11.4 & 169.1 & -58.9 \\
\hline ITAZ35 & 219.4 & 10.3 & 39.5 & -115.5 & -53.7 & 0.0 \\
\hline ITAZ38 & 232.9 & 4.1 & 9.8 & -42.2 & -104.5 & 0.0 \\
\hline ITAZMT & 362.9 & 36.8 & 27.0 & -141.3 & -185.4 & 0.0 \\
\hline
\end{tabular}


Table 4.4b Relative importance of dependent and explanatory variables in explaining per sector wage growth (in percentages) - from the 1980s onwards.

\begin{tabular}{|c|c|c|c|c|c|c|}
\hline Sector & $\begin{array}{l}\text { Constant } \\
(\%)\end{array}$ & $\begin{array}{l}\text { Technology } \\
(\%)\end{array}$ & Capital (\%) & Trade (\%) & Labour (\%) & $\begin{array}{l}\text { Residual } \\
(\%)\end{array}$ \\
\hline USAZMB & 0.0 & 2.3 & -0.7 & 4.7 & 100.7 & -7.1 \\
\hline USAZOP & 0.0 & 3.3 & 1.9 & 5.1 & 53.1 & 36.6 \\
\hline USAZOW & 0.0 & 6.9 & 1.4 & -3.1 & 57.4 & 37.3 \\
\hline USAZ35 & 72.6 & 17.0 & 1.5 & -6.1 & 21.4 & -6.4 \\
\hline FRAZOG & 0.0 & -0.3 & -27.6 & 2.8 & 137.3 & -12.2 \\
\hline FRAZOW & 0.0 & -26.7 & -43.1 & 4.0 & 216.6 & -50.9 \\
\hline FRAZMB & 0.0 & -4.1 & -0.2 & 3.2 & 83.2 & 17.9 \\
\hline DEUZ35 & 83.5 & 13.8 & -0.8 & 5.0 & 25.9 & -27.3 \\
\hline DEUZOG & -1367.3 & -22.0 & 5.6 & 2.7 & 1077.3 & 403.7 \\
\hline DEUZOP & 89.1 & -0.2 & -0.3 & -0.9 & 36.0 & -23.7 \\
\hline GBRZOO & 0.0 & -13.7 & 0.6 & 89.7 & 4.7 & 18.8 \\
\hline GBRZOW & 0.0 & 3.0 & -5.3 & 18.1 & 201.5 & -117.4 \\
\hline GBRZOP & 133.8 & -1.1 & 13.5 & 9.3 & -108.1 & 52.5 \\
\hline NLDZ38 & 0.0 & -11.6 & 8.3 & -64.8 & 980.6 & -812.5 \\
\hline NLDZMB & 0.0 & -107.2 & 3.2 & -1.4 & 153.1 & 52.3 \\
\hline NLDZMT & 349.8 & 44.8 & -4.3 & 11.3 & -178.9 & -122.8 \\
\hline ESPZLF & 0.0 & 35.6 & -7.7 & -3.0 & 55.9 & 19.1 \\
\hline ESPZMB & 0.0 & -0.7 & -2.2 & 2.7 & 98.3 & 1.9 \\
\hline ESPZOG & 0.0 & -3.7 & -3.2 & 9.8 & 88.6 & 8.5 \\
\hline ESPZOO & 0.0 & 27.9 & -3.6 & -13.6 & 44.4 & 45.0 \\
\hline ESPZOW & 0.0 & -10.6 & -3.8 & 9.0 & 61.9 & 43.5 \\
\hline ESPZMT & 0.0 & 14.4 & -1.3 & -28.5 & 121.9 & -6.5 \\
\hline ITAZLX & 0.0 & -0.1 & -6.2 & 34.0 & 85.1 & -12.8 \\
\hline ITAZMB & 0.0 & 0.1 & -3.7 & 10.5 & 108.9 & -15.8 \\
\hline ITAZ35 & 482.9 & 18.0 & 123.1 & -191.3 & -262.0 & -70.7 \\
\hline ITAZ38 & -236.9 & -4.4 & -14.0 & 58.2 & 287.6 & 9.6 \\
\hline ITAZMT & -326.0 & -35.2 & -24.8 & 147.3 & 295.9 & 42.7 \\
\hline
\end{tabular}




\subsection{The Case Of Imperfect Competition}

The approach that is followed in case of imperfect competition, is very similar to the one followed in the perfect competition case. We first ran OLS regressions ${ }^{37}$ on the basic model, which -from a theoretical point of view- now already contains a constant term. As long as $\alpha \leq 1$ and $\phi$ is in the elastic range $0>\phi>-1$, we expect $e_{1 a}$ and $e_{1 b}$ to have a negative sign, while $e_{0}, e_{3}$ and $e_{4}$ can have either sign (although $e_{3}$ is highly likely to be positive). The results of the estimations are shown in appendix B5.

We see that the constant term $\left(e_{0}\right)$ differs significantly from zero at the 5\% significance level only 17 times. These are all positive entries. Negative entries turn up only 13 times. A similar conclusion holds with respect to the coefficients of the import variables $\left(e_{1 a}\right.$ and $\left.e_{1 b}\right)$ : the coefficient for EU-imports differs significantly from zero 6 times, which are all positive entries but two. It has the desired sign 29 times. Non-European imports turn up significantly 10 times (of which two entries are negative), with a total of 24 negative signs. Thus, non-European imports, including those of the Asian NICs, may have a substantial impact on wage growth in some sectors. Given the construction of $e_{1 a}$ and $e_{1 b}$, they should have the same sign: a negative sign would indicate that $\alpha \leq 1$ (assuming that $\phi$ lies in the elastic range), a positive sign the opposite. This happens only 20 times.

Technology is significant only 3 times (of which one is a negative entry), and has a positive sign 44 times. The interest rate turns up significantly 3 times too, once with a negative sign. Negative signs occur 29 times in total.

Labour again is by far the most significant variable. It turns up so 49 times this time. All significant entries are positive ones; negative entries occur only 4 times. Given the highly non-linear way in which $\alpha, \beta$ and $\theta$ appear in the expressions of $e_{0-4}$, we cannot conclude whether there are increasing returns to scale or not. Yet, we can say something about this later on, when we analyze the sufficient condition put forward in the theoretical part.

As compared to the results presented in appendix B1, it is striking that for most sectors the fit improves: the imperfect-competition version of our model thus picks up some factors that were (unjustly) left out at the perfect competition stage.

In sum, we may state that for the larger part of the sectors, the assumption that $\alpha \leq 1$ probably does not hold. Although in principle the violation of the assumption does not pose a big problem per $\mathrm{se}^{38}$, it may again be that there are structural breaks underlying the results. Therefore, we performed a Chow structural break test

37. NLS and ML regressions were also tried (with the results from the OLS regressions as starting values), but this yielded hardly any result (convergence occurred in only two cases when applying NLS, whereas in case of ML, no convergence occurred).

38. As long as $\alpha(\phi+1) \leq 1$ (as indicated in section 2). Yet, the 'conflict' in sign between the two import variables may lead us to the conclusion that even the current specification leaves something to be desired. Do note however, that this sign 'conflict' may be due to multicollinearity: the two import variables have a correlation that is mostly larger than .60 (and often exceeds .80). Although there are solutions to multicollinearity (for example, dropping one of the collinear variables), this is not an option in the present context. 
for (mostly) the years 1981 and 1985 and checked whether such breaks were present $^{39}$.

Structural breaks were found for 8 sectors: three German (paper and printing, total manufacturing and other manufacturing industries), one French (fabricated metal products), one American (basic metals), two Italian (food, drink and tobacco and other manufacturing industries) and a Dutch one (basic metals). For only four of them, we also found structural breaks in the perfect competition case ${ }^{40}$. The estimation for these sectors was redone, with the estimation period now mostly starting in 1980 or $1981^{41}$. The revised regression results are presented in appendix B6. Note that the results are split into two groups: the cases where employment growth determines wage growth, and the cases where wage growth determines employment growth ${ }^{42}$.

Of course, the only changes that occur are for the aforementioned 8 sectors. One striking result emerges: if sign switches arise, they now generally do not point into the desired direction (assuming that $\alpha \leq 1$ ). This is mainly due to the two import variables, that switch signs for some of the 8 sectors in such a way, that they become opposite.

Nevertheless, it remains quite difficult to be more specific about the results without actually knowing the values of the parameters $\alpha, \beta, \delta, \varepsilon, \theta, \phi$ and $\hat{B}$. Therefore, we put the estimated coefficients of the imperfect-competition model in the general expressions depicted in the theoretical part, and solve the system of equations we get for $e_{0-4}$ numerically. To ensure that we have a system of six equations for six unknowns (which hopefully can be solved), $\alpha(\phi+1), \beta(\phi+1)$ and $\frac{\phi(\beta-\theta)}{1-\alpha-\beta}$ are taken as single coefficients. The outcome of this procedure is shown in appendix B7.

We may recall from section 2 that there are several conditions which have to hold in order to fulfill the requirements of the model. These conditions are that $\delta, \varepsilon<0$ and that $\alpha(\phi+1), \beta(\phi+1)>0 . \delta$ is smaller than zero 21 times, while $\varepsilon$ is so even 36 times. However, when taken together, they are negative only 4 times. A similar conclusion is reached for the $\alpha(\phi+1)$ and $\beta(\phi+1)$ terms: the first one is almost

39. Why these years were chosen has been set out in section 4.1 .

40 . These sectors are the German and Italian other manufacturing industries, total manufacturing in Germany and the French food, drink and tobacco sector.

41. Exceptions are the French fabricated metal products and the American basic metals industries. For these sectors, the estimation period started in 1986. In the French case, an insufficient number of observations was left to estimate the equation. Therefore, this sector was excluded from further analysis.

42. The results of Granger causality tests in appendix B4 are still valid. 
always positive (in 65 out of 66 cases) ) $^{43}$, while the latter is positive 40 times. But together they have a positive value on just 26 occasions. The growth rate of the exogenous shift variable $B$ receives a negative value 29 times, indicating that in about half of our cases, the demand function is indeed shifted towards lower prices.

Combining the results for $\delta, \varepsilon, \alpha(\phi+1)$ and $\beta(\phi+1)$, we find that only one sector fulfills all requirements: fabricated metal products in the Netherlands. Here, we may even conclude that increasing returns to scale are at work, for the sum of $\alpha(\phi+1)$ and $\beta(\phi+1)$ equals 1.12. When we only look at the question whether there are increasing returns, our sufficient condition tells us that this is the case for 26 sectors. Especially in Germany and the US, increasing returns are found ${ }^{44}$. On the contrary, we find no indication of increasing returns in Spain. $M_{e u}$ depresses prices as often as $M_{\text {neu }}$ if we only look at the four cases where both $\delta$ and $\varepsilon$ are negative $(\delta<\varepsilon$ twice $)$.

Another interesting result is that in absolute terms, $\beta(\phi+1)$ is larger than $\alpha(\phi+1)$ in 48 out of 66 cases. Given the predominance of negative signs for the $\beta(\phi+1)$ term $^{45}$ (whereas $\alpha(\phi+1)$ is positive in all but one case), this not only implies that, if $(\phi+1)>0, \beta<\alpha$ in most cases, but also that $\beta<0$. While the first result says that the marginal return to capital is larger than the marginal return to labour (which may very well be true), the second result obviously undermines the complete imperfect competition model: negative marginal returns to either variable are simply out of the question. Furthermore, if $(\phi+1)<0, \alpha$ would take on negative values (and $\beta$ would have the expected sign), and a monopoly solution would be excluded. Although this may cast some doubt on the validity of our model, we should not forget the fact that we are still -and always will be- faced with an aggregation problem, which clearly can have distorted our results (even if the model were correct in itself).

\section{Policy Conclusions}

Under perfect competition and the small country assumption protectionism is damaging. It is here where the whole discussion has its policy relevance. Firms and sectors ask governments for protectionism or for compensation for losses from trade. One such policy action has been the Trade Adjustment Assistance Program in the US. Sachs and Shatz (1994) show that the sectoral distribution of compensations from that program are strongly correlated with the underlying sectoral distribution of sectoral employment losses. In our analysis of the perfect competition case we found that 11 (15) of the sectors that have a negative effect from adverse terms of trade movements have decreasing wages. The crucial question is then whether income policies for the short run and $R \& D$ subsidies for the long run would be a better means to help these sectors than protectionism. As international

43. With food, drink and tobacco in the Netherlands as the exception.

44. Exceptions are paper and printing in Germany and basic metals, leather products and wood, cork and furniture in the US.

45. It has a negative sign 39 times. 
trade has gained in importance since the 1980s this question has become more urgent.

However, it should be clear that behind the given interest rate there is a critical issue of interest rate determination and behind the given sectoral labour supply and wages there are labour market imperfections. Given the dominance of the labour supply variable in both the perfect and the imperfect competition version of our model, it seems reasonable to search for a diagnosis and a solution to problems in the labour market sphere. There, specific factors have turned out to be a robust variable, which is more important than both technology and trade.

\section{Limitations}

The major drawback of a trade-theoretic approach is that international trade models are not related to models explaining unemployment and vice versa. The state of the art in the literature thus seems to be somewhat unsatisfactory. This is the reason why economists currently have to choose between a closed economy labour market imperfections approach and a first-best trade approach. The integration of the two must be left for further research. Moreover, due to the simplifying assumption of constant price elasticities of demand and therefore of mark-ups over marginal costs, we cannot include their change across the business cycle without considerably complicating the model.

An incentive for further research from our analysis follows from three results. First, in the perfect competition case the constant term in our model was absent but the empirics tell us that we should have one (thus indicating that there are possibly other explanatory variables that should have been included in the model). Second, the model would predict relations between the coefficients, but the corresponding constraint has been rejected by statistical tests. Third, we could not exclude increasing returns to scale in case of perfect competition, while we only found some preliminary evidence hereof in the imperfect competition case. Nevertheless, as can be concluded from the rejection of the imposed constraint and the unsatisfactory results reached in the imperfect competition case, we are still faced with an aggregation problem. Thus, we cannot actually prove that the assumption of perfect competition is wrong. So, even if our model and estimation results are rather crude to give a 'robust' answer to the question what factor drives sectoral wage growth most strongly (technology or trade), our results do have some relevance. In particular, the supply of specific factors turned out to matter in both models and the changing role of international trade (becoming more important than technology in the 1980s according to the perfect competition model) became quite clear. 


\section{References}

Alier, J.M. (1997), 'Ecological Economics and Environmental Policy: a Southern European View'. In: Tylecote, A.B. and van der Straaten, J.C. (ed.), Environment, Technology and Economic Growth: the Challenge to Sustainable Development, Edward Elgar Publishing Company, Aldershot, 1997.

Baldwin, R.E. and Cain, G.G, 'Shifts in U.S. Relative Wages: the Role of Trade, Technology and Factor Endowments', NBER WP 5934 (1997).

Bovenberg, L, 'Environmental Taxation and Employment', De Economist 143 (1995), no.2.

Caniëls, M.C.J., 'The Geographic Distribution of Patents and Value Added across European Regions', Paper Presented at the $37^{\text {th }}$ European Congress of the European Regional Science Association, Rome, August 26-29 1997.

Chow, G.C., 'Tests of Equality between Sets of Coefficients in Two Linear Regressions', Econometrica 28 (1960), pp. 591-605.

Eels, E., Probabilistic Causality, Cambridge University Press, Cambridge, 1991.

Freeman, R. B., 'Are your Wages set in Beijing?', Journal of Economic Perspectives 9 (1995), pp. 15-32.

Feldman, M.P. and Florida, R., 'The Geographic Sources of Innovation: Technological Infrastructure and Product Innovation in the United States', Annals of the Association of American Geographers 84 (1994), pp. 210-229.

Francois, J.F. , 'Trade, Labour Force Growth and Wages', The Economic Journal 106 (1996), pp. 1586-1609.

Gallant, A.R. and Fuller, W.A., 'Fitting Segmented Polynomial Regression Models whose Joint Points have to be Estimated', Journal of the American Statistical Association 68 (1973), pp. 144-147.

Granger, C.W.J., 'Investigating Causal Relations by Econometric Models and CrossSpectral Methods', Econometrica 44 (1969), pp. 424-438.

Griliches, Z., 'Patent Statistics as Economic Indicators: a Survey', Journal of Economic Literature 28 (1990), pp. 1661-1707.

International Financial Statistical Yearbook 1990, Publication of the IMF, International Monetary Fund Publication Services, Washington, 1990. 
International Financial Statistical Yearbook 1995, Publication of the IMF, International Monetary Fund Publication Services, Washington, 1995.

Jones, R.W., 'The Role of Technology in The Theory of International Trade'. In: Vernon, R. (ed.), The Technology Factor in International Trade, NBER, New York, 1970.

Krugman, P.R., 'Competitiveness: a Dangerous Obsession', Foreign Affairs, March/April 1994.

Krugman, P.R. and Lawrence, R.Z., 'Trade, Jobs and Wages', NBER WP 4478 (1993).

Krugman, P.R. and Obstfeld, M., International Economics, $4^{\text {th }}$ edition, AddisonWesley Publishing Company, Reading, 1997.

Lawrence, R.Z. and Slaughter, M.J., 'International Trade and American Wages in the 1980s: Giant Sucking Sound or Small Hiccup', Brookings Papers on Economic Activity, 2 (1993), pp. 161-226.

Leamer, E.E., 'Wage Inequality from International Competition and Technological Change: Theory and Country Experience', American Economic Review, AEA Papers and Proceedings, May 1996.

Leamer, E.E., 'Trade, Wages and Revolving Door Ideas', NBER WP 4716 (1994).

Leamer, E.E., 'Wage Effects of a U.S. Mexican Free Trade Agreement'. In: Garber, P.M. (ed.), The Mexico-U.S. Free Trade Agreement, MIT Press, Cambridge, 1993.

Lücke, M., 'European Trade with Lower-Income Countries and the Relative Wages of the Unskilled: an Exploratory Analysis for West-Germany and the UK', Kiel University WP 819 (1997).

Oliveira Martins, J., 'Market Structure, Trade and Industry Wages', OECD Economic Studies No. 22, Spring 1994, pp. 131-154.

Oscarsson, E., 'Trade and Relative Wages in Sweden 1968-91', Department of Economics, Stockholm University Research Memorandum, January 1997.

Richardson, J.D., 'Income Inequality and Trade: How to Think, What to Conclude', Journal of Economic Perspectives 9 (1995), pp. 33-55.

Sachs, J.D. and Shatz, H.J., 'Trade and Jobs in U.S. Manufacturing', Brookings Papers on Economic Activity 1 (1994), pp. 1-84. 
Scherer, F.M., 'The Propensity to Patent', International Journal of Industrial Organization 1 (1983), pp. 107-128.

Sims, C.A., 'Money, Income and Causality', American Economic Review 62 (1972), pp. 540-555.

White, H., 'A Heteroscedasticity-Consistent Covariance Matrix Estimator and a Direct Test for Heteroscedasticity', Econometrica 48 (1980), pp. 817-838.

Wood, A., North-South Trade, Employment and Inequality, Clarendon Press, Oxford, 1994.

'How Trade Hurt Unskilled Workers', Journal of Economic Perspectives 9 (1995), pp. 57-80. 


\section{APPENDIX A1}

\section{Data Description}

All data, except the Spanish data, data on long-term interest rates and data on technical change, are taken from the OECD's ISDB database. Employment data contain the number of employees, excluding the self-employed. Wages contain all payments made to wage and salary earners ${ }^{1}$, including social security payments. Both sectoral and national prices are also calculated from the ISDB database, via value added at market prices (with 1985 as a base year). Technically speaking, it would have been preferable to use value added at factor costs to construct price levels, for this would exclude taxes and subsidies, which may differ between countries. Only for Great-Britain value added was available at factor costs in the database (and subsequently used). All variables are expressed in national price levels.

All interest data are taken from the International Financial Statistics Yearbook published by the IMF (from 1990 and 1995 publications). The long-term government bond yield was taken as a proxy for the long-term interest rate ${ }^{2}$.

As a proxy of technical change, $R \& D$ expenditures are used ${ }^{3}$. These data are taken from the OECD's ANBERD database.

For Spain, employment, wage and sectoral price levels are calculated from the OECD's STAN database. Spanish employment figures do include the selfemployed. R\&D data are again taken from ANBERD, whereas both national price levels (the GDP deflator) and the interest rate data are taken from the International Financial Statistics Yearbook. All import data are from the OECD's BITRA database.

The sectors included in the analysis are the 2-digit ISIC sectors 31 through 39 , which define total manufacturing (ISIC sector 30). In the remainder, we will denote these sectors by means of an abbreviation. These abbreviations are:

\footnotetext{
1. Which also do not include the self-employed.

2. As suggested by the IMF itself, cf. the International Financial Statistics Yearbook 1995 (1995), pp. $x v-x v i$.

3. One may claim that because $R \& D$ personnel is included in the labour variable, our regression results are biased (since we are also using $R \& D$ expenditures as a separate variable). However, this only means that there may be some collinearity between the $R \& D$ and labour variable (which is justified from a theoretical point of view). Regression results do not become biased because of collinearity.
} 
Table A.1.1 Sector classification and abbreviations.

\begin{tabular}{||lll||}
\hline ISIC code & Abbreviation & Sector description \\
30 & ZMT & \\
31 & ZLF & Total manufacturing \\
32 & ZLX & Food, drink and tobacco \\
33 & ZOW & Textiles, footwear and leather \\
34 & ZOP & Wood, cork and furniture \\
35 & Z35 & Paper and printing \\
36 & ZOG & Chemicals \\
37 & ZMB & Stone, clay and glass \\
38 & Z38 & Basic metals \\
39 & ZOO & Fabricated metal products, machinery and equipment \\
\hline
\end{tabular}

Furthermore, the following country codes will be used from here onwards:

Table A.1.2 Country codes.

\begin{tabular}{||ll||}
\hline Country & Country code \\
USA & USA \\
Former West-Germany & DEU \\
France & FRA \\
Great-Britain & GBR \\
The Netherlands & NLD \\
Italy & ITA \\
Spain & ESP \\
\hline
\end{tabular}

In the regression analyses, three sectors were dropped because of missing $R \& D$ data: the Dutch and Italian wood, cork and furniture sector and the Dutch other manufacturing industries. 


\section{APPENDIX A2}

\section{Growth Rates}

Below, an overview of mean growth rates of the variables included in our model can be found. The period over which means are taken is motivated by the estimation periods of the 'final' regressions depicted in appendix B3. The table is divided into two parts: first, the results for the US, Germany, France and GreatBritain are shown, whereafter the results for the Netherlands, Spain and Italy follow.

Table A.2.1 Mean growth rates for the US, Germany, France and Great-Britain (sample period according to appendix B3, variable definitions according to the regression equation and appendix B1).

\begin{tabular}{|c|c|c|c|c|}
\hline SECTOR & $\mathbf{L}$ & $\mathbf{W}$ & $\mathbf{P}$ & $\mathbf{A}$ \\
\hline DEUZ35 & 0.0034 & 0.0248 & 0.0026 & 0.0308 \\
\hline DEUZLF & -0.0034 & 0.0099 & -0.0038 & 0.0651 \\
\hline DEUZLX & -0.0435 & -0.0222 & -0.008 & 0.0583 \\
\hline DEUZMB & -0.0157 & -0.0003 & -0.0135 & 0.0026 \\
\hline DEUZOG & -0.0178 & 0.0009 & -0.0064 & 0.0684 \\
\hline DEUZOP & -0.0031 & 0.0153 & 0.0025 & 0.0789 \\
\hline DEUZOW & -0.006 & 0.0091 & 0.0086 & 0.4281 \\
\hline GBRZ35 & -0.0168 & 0.0112 & -0.0112 & 0.0462 \\
\hline GBRZ38 & -0.0244 & -0.0067 & -0.0073 & -0.1341 \\
\hline GBRZLF & -0.0212 & 0.0046 & -0.0047 & -0.0886 \\
\hline GBRZLX & -0.0428 & -0.0188 & -0.0121 & -0.0886 \\
\hline GBRZMT & -0.0283 & -0.0047 & -0.0061 & 0.0127 \\
\hline GBRZOO & -0.0253 & 0.0209 & 0.0359 & -0.0019 \\
\hline GBRZOP & -0.0101 & 0.0107 & 0.006 & -0.0022 \\
\hline GBRZOW & -0.0152 & -0.0077 & -0.0007 & -0.0019 \\
\hline GBRZMB & -0.0571 & -0.0336 & -0.0064 & -0.0955 \\
\hline GBRZOG & -0.0399 & -0.0026 & -0.0225 & -0.0637 \\
\hline DEUZ38 & 0.0059 & 0.0223 & -0.0014 & 0.042 \\
\hline DEUZOO & -0.0216 & 0.0013 & -0.0002 & 0.0243 \\
\hline DEUZMT & -0.0063 & 0.009 & -0.001 & 0.0294 \\
\hline USAZ35 & 0.0063 & 0.0179 & -0.0019 & 0.0455 \\
\hline USAZ38 & -0.0036 & 0.0062 & -0.0156 & 0.0126 \\
\hline USAZLF & -0.002 & 0.0048 & 0.0023 & 0.0294 \\
\hline
\end{tabular}




\begin{tabular}{|c|c|c|c|c|}
\hline SECTOR & $\mathbf{L}$ & W & $\mathbf{P}$ & $\mathbf{A}$ \\
\hline USAZLX & -0.0199 & -0.0145 & -0.0265 & 0.032 \\
\hline USAZMB & -0.0286 & -0.0222 & 0.0015 & -0.0049 \\
\hline USAZMT & -0.0045 & 0.0047 & -0.0085 & 0.0187 \\
\hline USAZOG & -0.0134 & -0.008 & -0.0076 & 0.0105 \\
\hline USAZOO & -0.0067 & 0.0018 & -0.0048 & 0.0041 \\
\hline USAZOP & 0.0108 & 0.0179 & 0.0052 & 0.0522 \\
\hline USAZOW & 0 & 0.0046 & -0.0056 & 0.0209 \\
\hline FRAZLX & -0.0393 & -0.0195 & -0.0019 & -0.0056 \\
\hline FRAZMB & -0.0257 & -0.0219 & -0.0196 & 0.0791 \\
\hline FRAZOO & -0.0053 & 0.0034 & 0.0008 & 0.0752 \\
\hline FRAZOP & -0.0016 & 0.018 & 0.0087 & 0.0227 \\
\hline FRAZ35 & -0.006 & 0.003 & -0.0079 & 0.0458 \\
\hline FRAZ38 & -0.0149 & 0.0004 & -0.0035 & 0.0507 \\
\hline FRAZLF & 0.0003 & 0.0057 & -0.0028 & 0.0686 \\
\hline FRAZMT & -0.016 & -0.0025 & -0.0035 & 0.0487 \\
\hline FRAZOG & -0.0279 & -0.0129 & -0.0023 & 0.0234 \\
\hline FRAZOW & -0.0235 & -0.0082 & -0.0051 & 0.0779 \\
\hline DEURATE & -0.0003 & SMPL: 74-92 & & \\
\hline GBRRATE & -0.0001 & $74-92$ & & \\
\hline GBRRATE2 & 0.0026 & $74-89$ & & \\
\hline GBRRATE3 & 0.0001 & $86-92$ & & \\
\hline USARATE & -0.0012 & $74-93$ & & \\
\hline FRARATE & -0.0034 & $74-91$ & & \\
\hline FRARATE2 & -0.0052 & $80-91$ & & \\
\hline
\end{tabular}


Table A.2.2 Mean growth rates for the Netherlands, Spain and Italy (sample period according to appendix B3, variable definitions according to the regression equation and appendix B1).

\begin{tabular}{|c|c|c|c|c|}
\hline SECTOR & $\mathbf{L}$ & $\mathbf{W}$ & $\mathbf{P}$ & $\mathbf{A}$ \\
\hline NLDZLF & -0.0115 & 0.0042 & -0.0099 & 0.0415 \\
\hline NLDZLX & -0.0495 & -0.0353 & -0.0054 & -0.0074 \\
\hline NLDZMB & -0.0139 & -0.0015 & -0.0083 & 0.0234 \\
\hline NLDZMT & -0.0123 & 0.0028 & -0.0095 & 0.0187 \\
\hline NLDZOP & -0.0006 & 0.0134 & -0.0064 & 0.0126 \\
\hline NLDZ35 & 0.0088 & 0.0185 & 0 & 0.0453 \\
\hline NLDZ38 & -0.0053 & 0.0013 & 0.0025 & 0.0428 \\
\hline NLDZOG & -0.0146 & -0.0022 & 0.0035 & 0.0405 \\
\hline ESPZ35 & -0.0184 & -0.0056 & -0.0019 & 0.0824 \\
\hline ESPZ38 & -0.0001 & -0.0026 & -0.0026 & 0.1399 \\
\hline ESPZLF & -0.0085 & 0.0092 & -0.0188 & 0.111 \\
\hline ESPZLX & -0.0333 & -0.0361 & -0.0088 & 0.1199 \\
\hline ESPZMB & -0.0399 & -0.0323 & -0.0339 & 0.0173 \\
\hline ESPZOG & -0.0221 & -0.0159 & 0.0005 & 0.047 \\
\hline ESPZOO & -0.0129 & 0.0017 & -0.0489 & 0.5407 \\
\hline ESPZOP & 0.0099 & 0.023 & 0.0089 & 0.1171 \\
\hline ESPZOW & -0.0189 & -0.0173 & -0.0047 & 0.5935 \\
\hline ESPZMT & 0.0172 & 0.0128 & -0.0227 & 0.1177 \\
\hline ITAZ35 & -0.0046 & 0.0113 & -0.0488 & 0.0409 \\
\hline ITAZ38 & -0.0092 & 0.0101 & -0.0181 & 0.0521 \\
\hline ITAZLF & -0.0091 & 0.0084 & -0.015 & 0.0883 \\
\hline ITAZLX & -0.0139 & -0.001 & -0.01 & 0.1614 \\
\hline ITAZMB & -0.0234 & -0.0104 & -0.0176 & 0.0847 \\
\hline ITAZMT & -0.0108 & 0.0068 & -0.0193 & 0.0468 \\
\hline ITAZOG & -0.0108 & 0.0079 & -0.0112 & 0.0978 \\
\hline ITAZOP & -0.0037 & 0.0128 & -0.0157 & 0.0307 \\
\hline ITAZOO & -0.0208 & -0.0101 & 0 & 0.1913 \\
\hline NLDRATE & -0.0028 & SMPL: 74-93 & & \\
\hline NLDRATE2 & 0.0003 & $81-93$ & & \\
\hline ITARATE & -0.0057 & $74-94$ & & \\
\hline ITARATE2 & -0.0081 & $81-94$ & & \\
\hline
\end{tabular}




\begin{tabular}{||l|r|r|l|l||}
\hline SECTOR & & & & \\
\hline \hline ESPRATE & -0.0064 & SMPL: $80-91$ & & \\
\hline ESPRATE2 & 0.0013 & $86-91$ & & \\
\hline
\end{tabular}




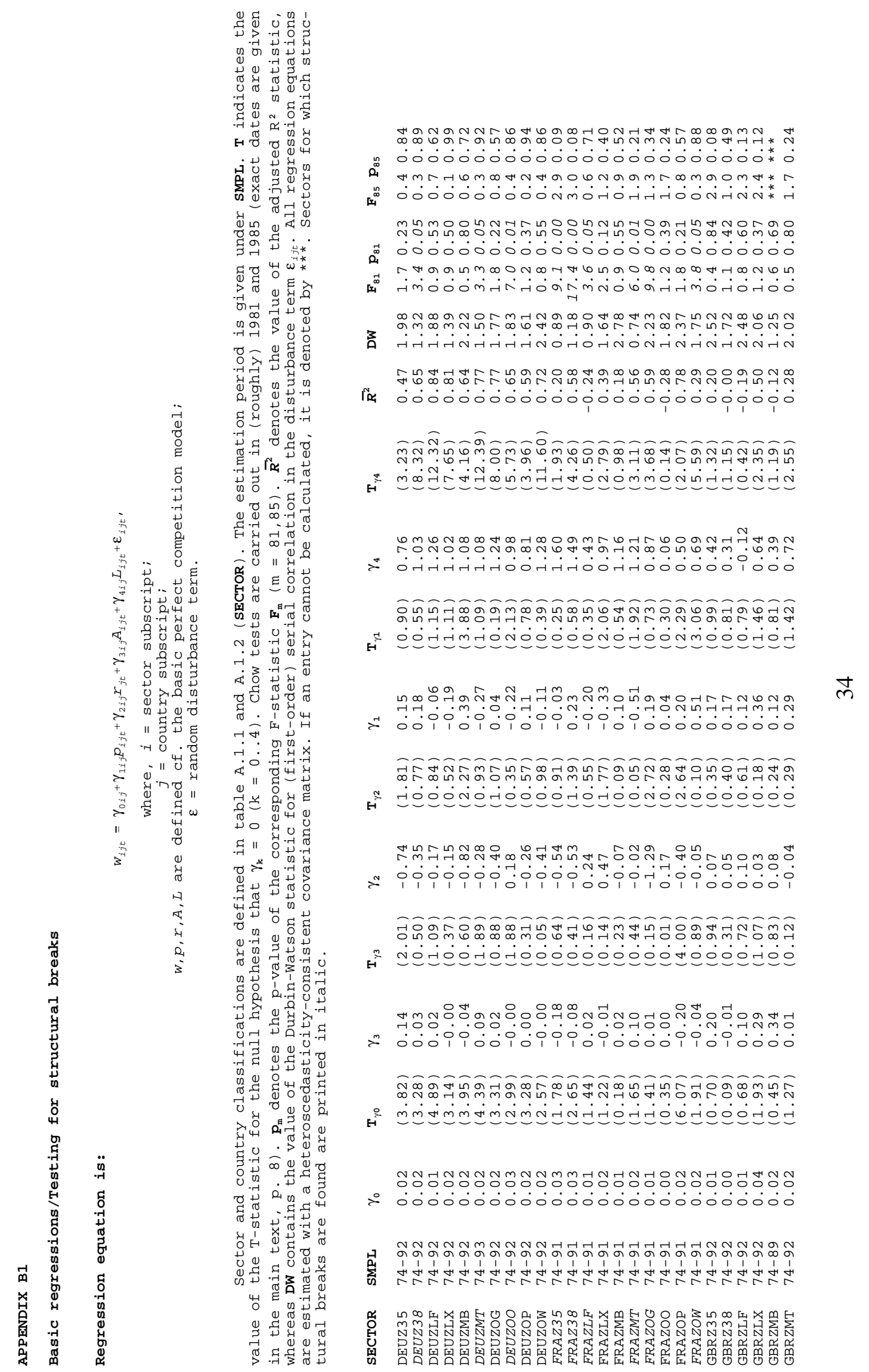




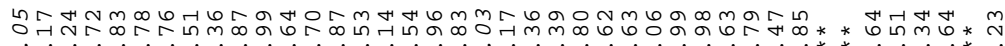

.

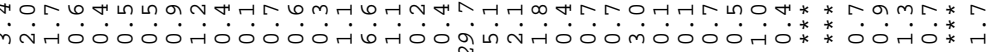

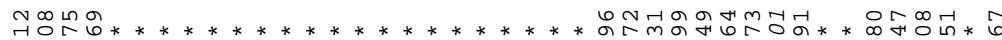

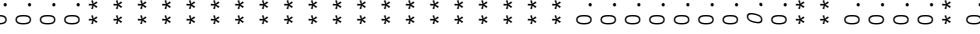
苟

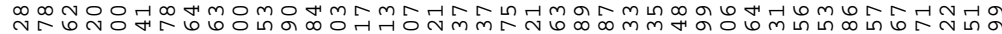

दू

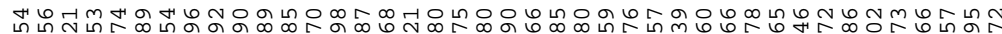

Tै 0.000000000000000000000000000000000000000 ลำ

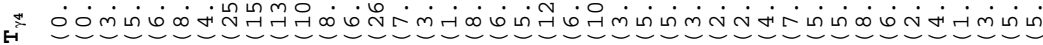

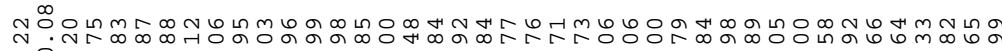

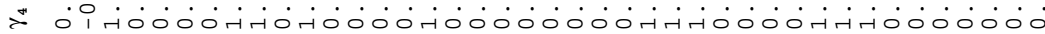

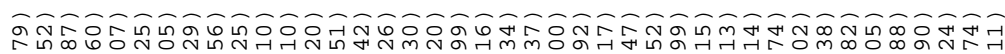

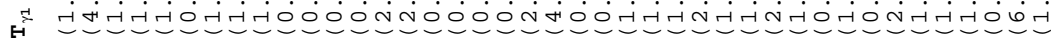

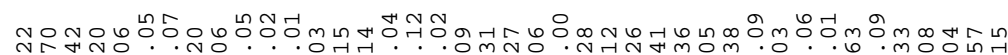

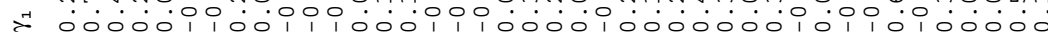

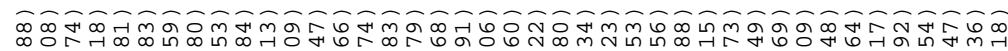
क o صำ

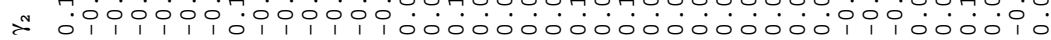

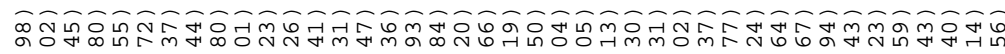
के

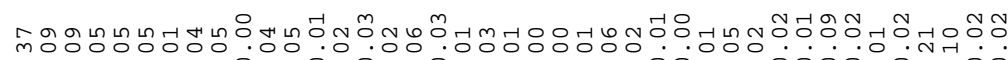

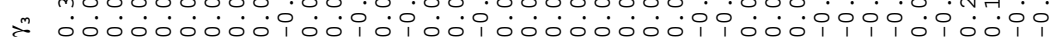

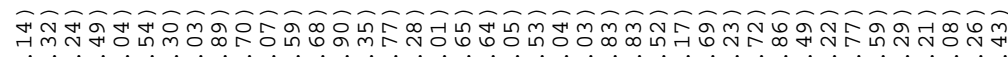

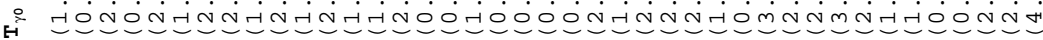

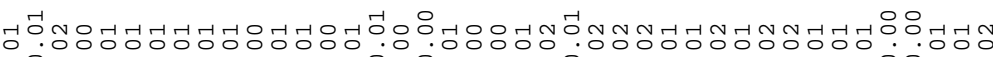

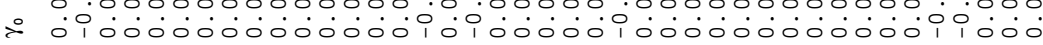

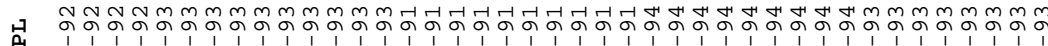

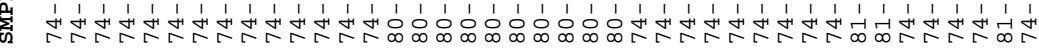

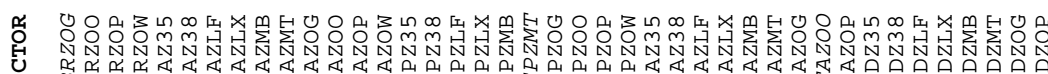

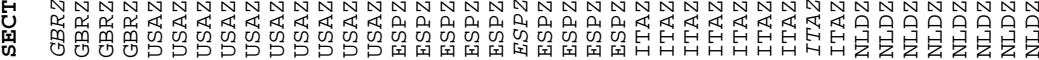




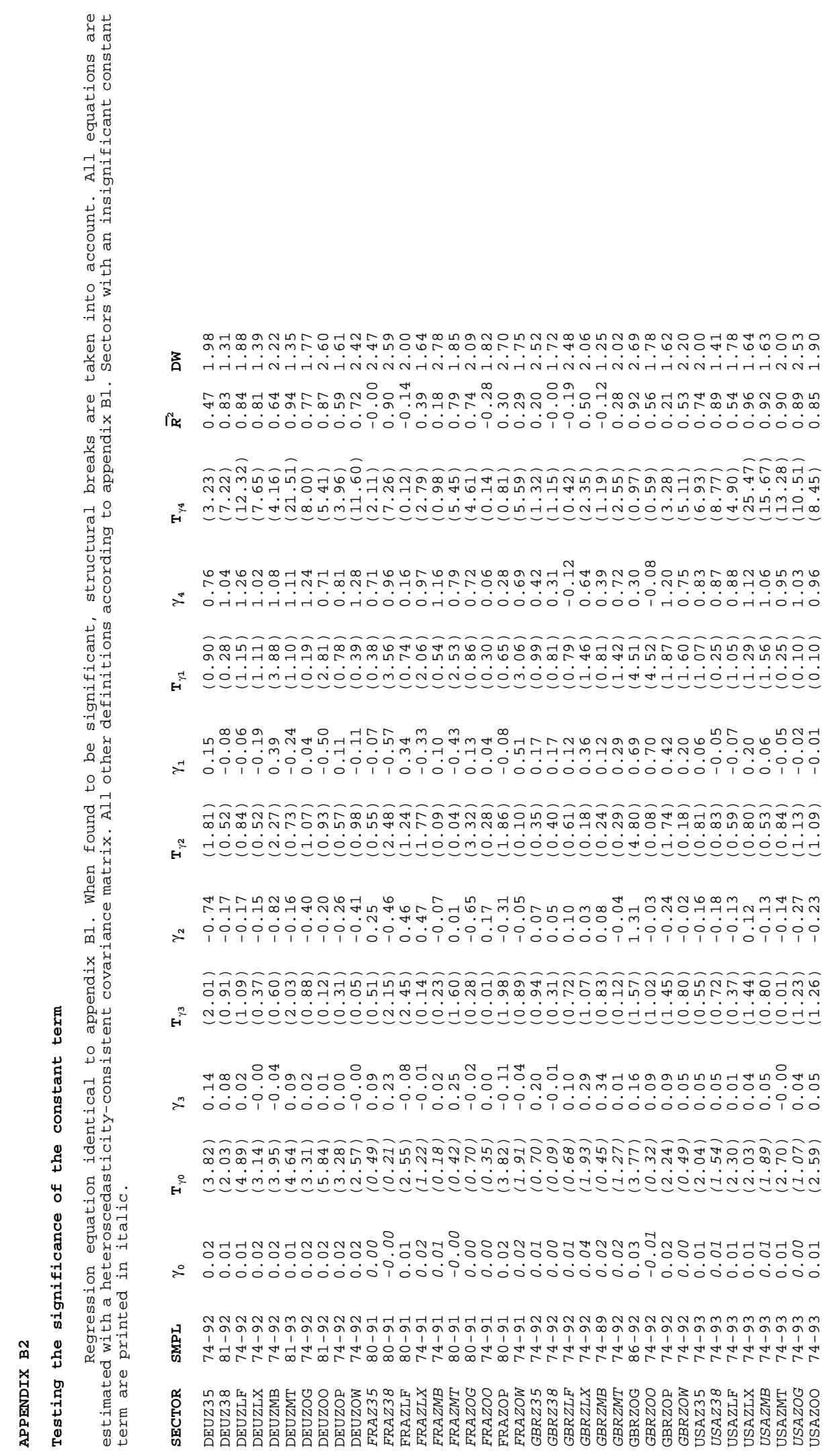




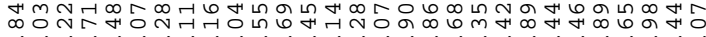

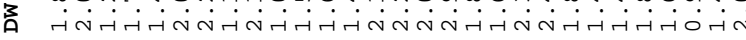

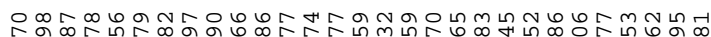

Tै 0.0000000000000000000000

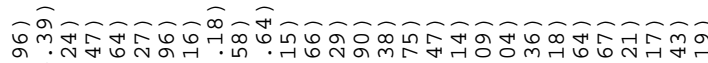

Fं

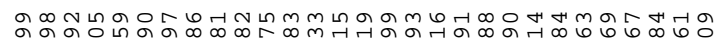

- ठ0.

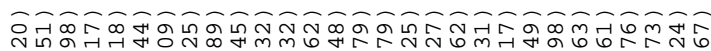

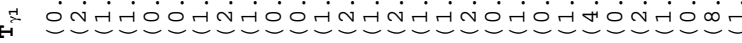

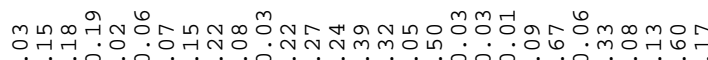

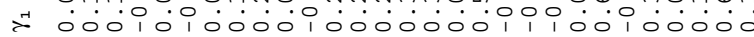

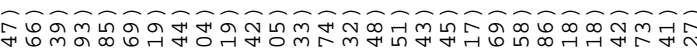

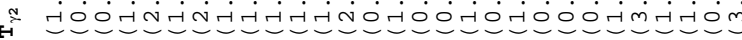

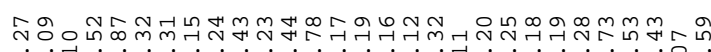

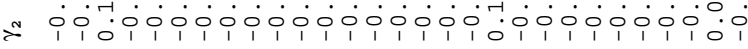

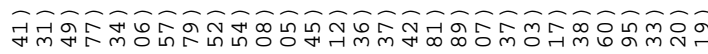

\% o

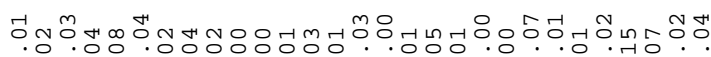

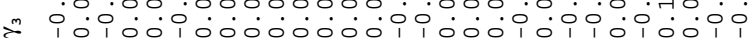

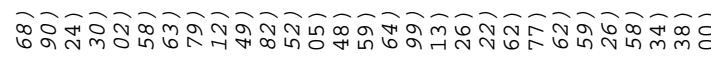

क्ष

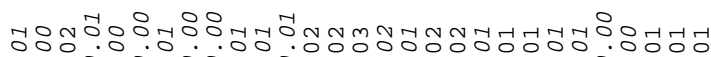

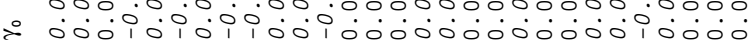

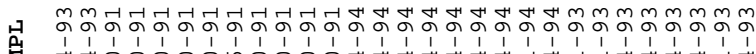

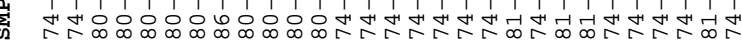

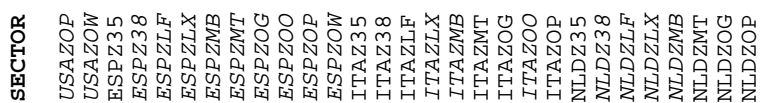




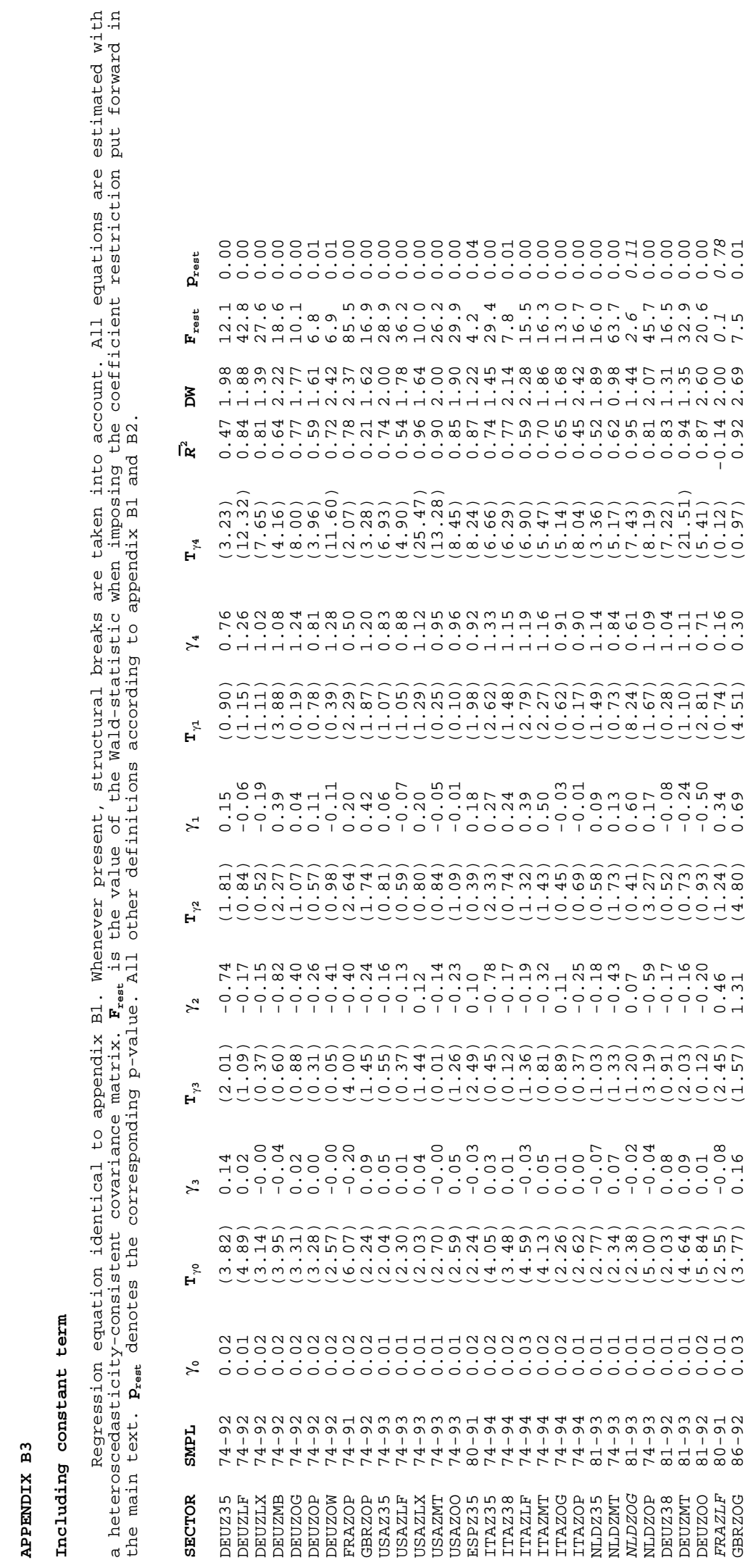




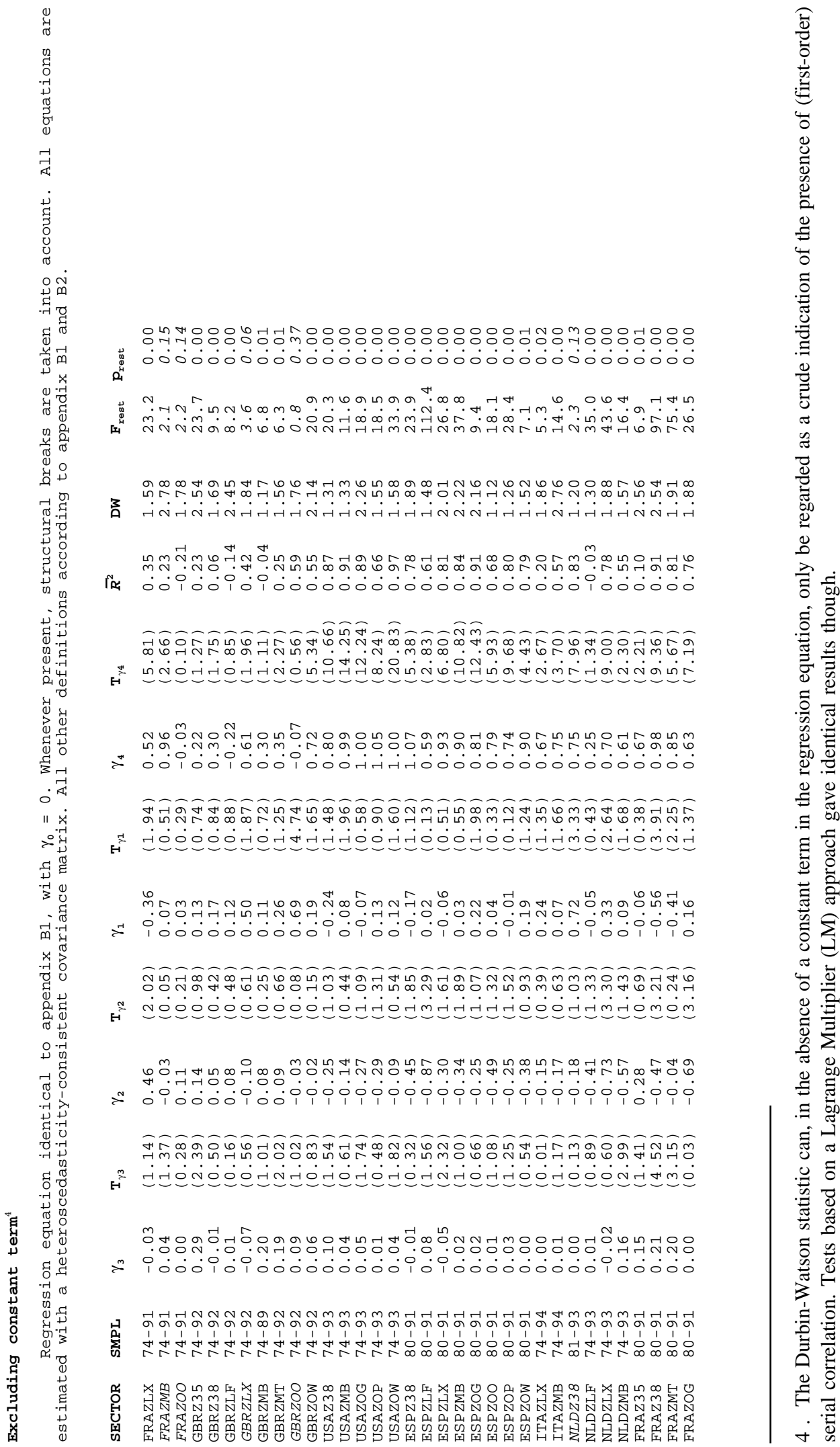




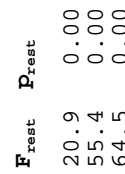

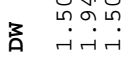

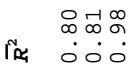

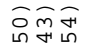

คै

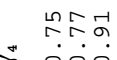

ธิศ్య

F

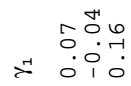

ศำ

कै

๓กำ

$\approx$ i i

근ำ

कै घंอे

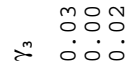

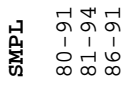

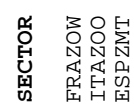




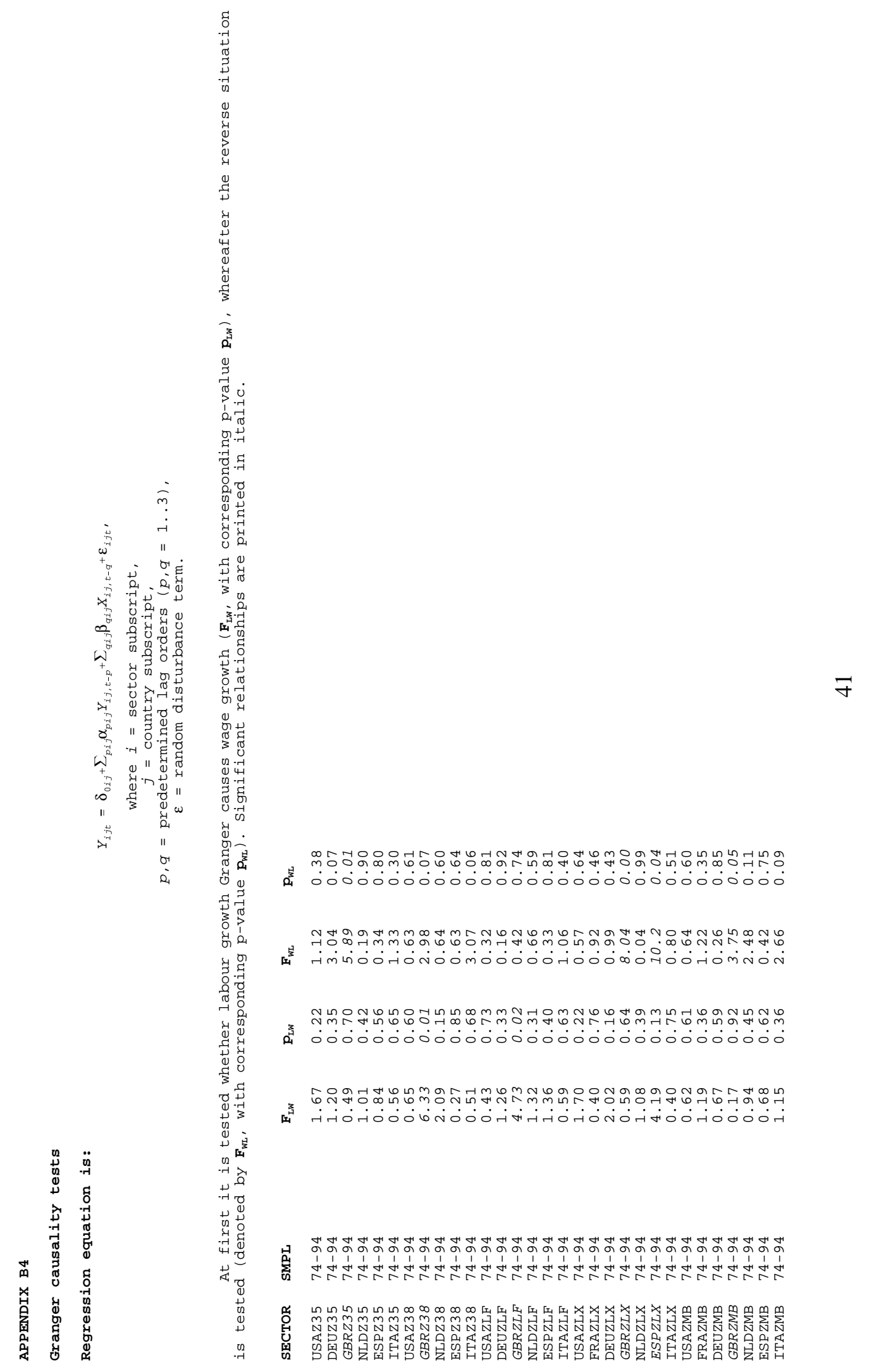




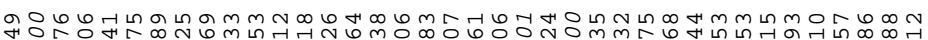

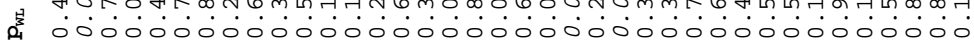

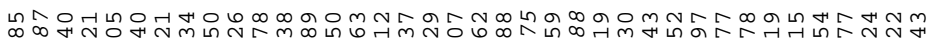

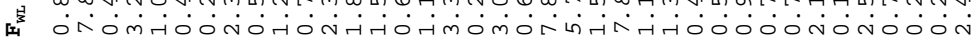

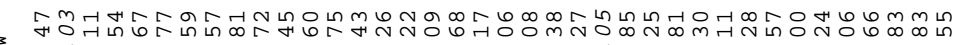

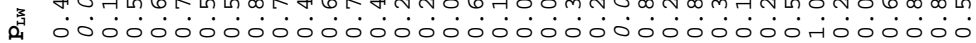

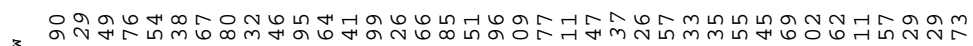

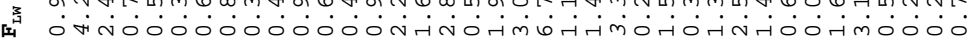

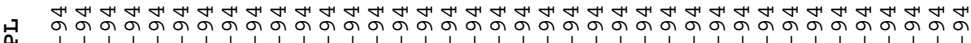

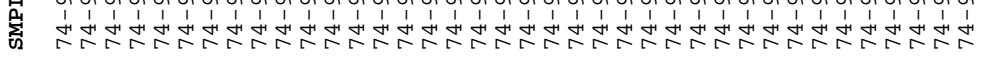

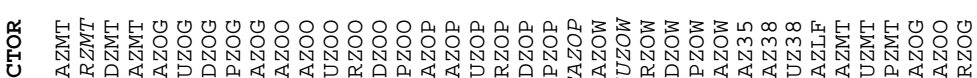

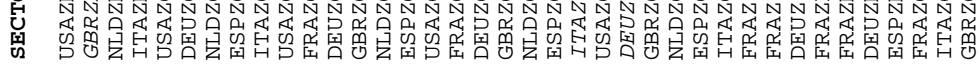




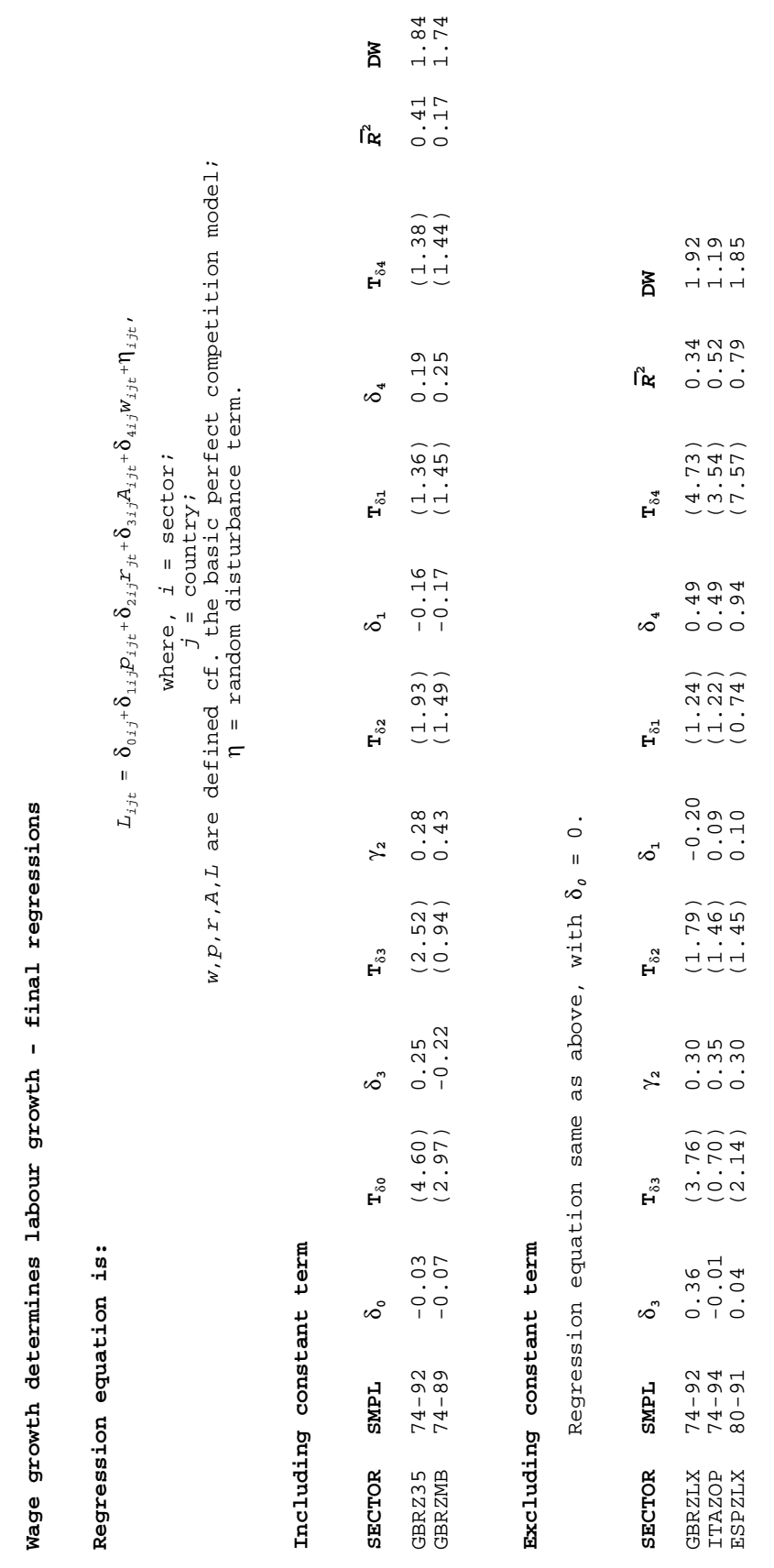




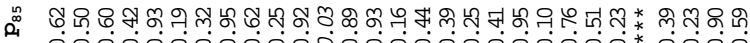

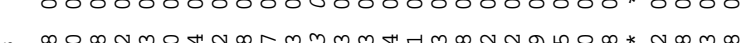

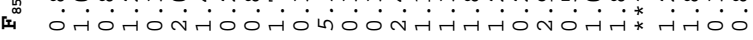

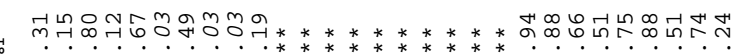

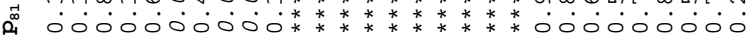

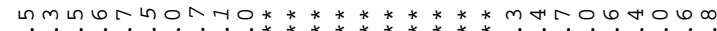

蛙

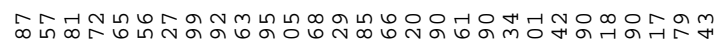

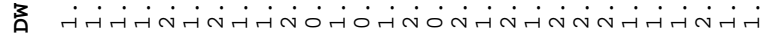

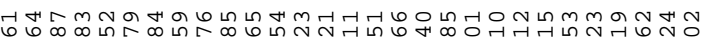

Th o00000000000000000000000

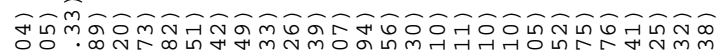

ثं ம்

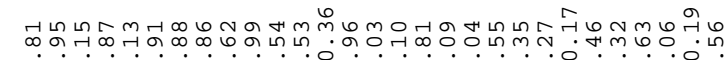

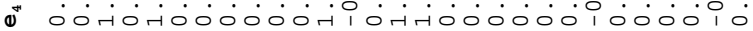

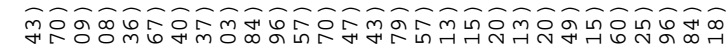
н

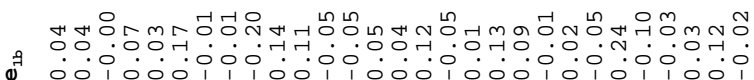

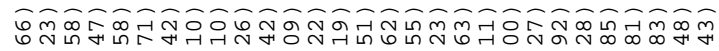
ث:

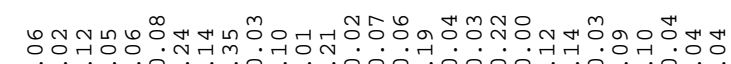

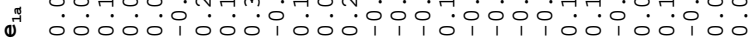

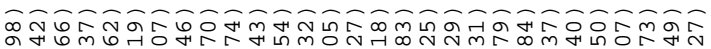

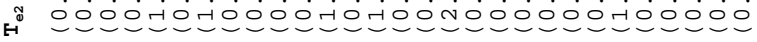

mำ

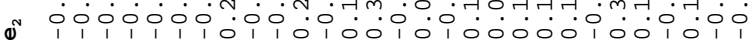

Oด๊ н घo

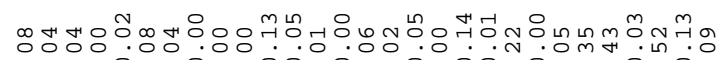

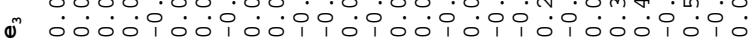

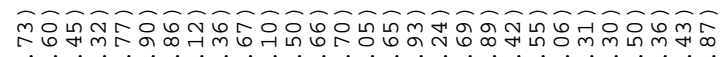
њ

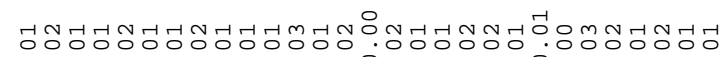

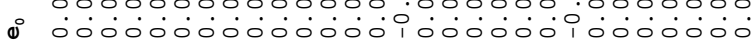

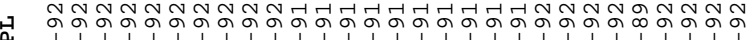

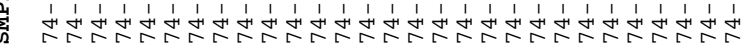

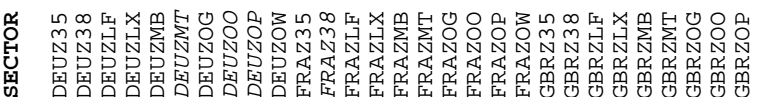




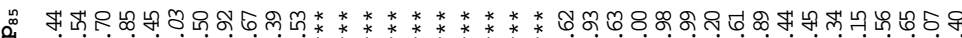

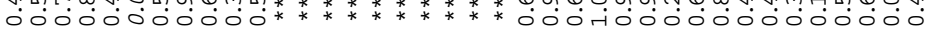

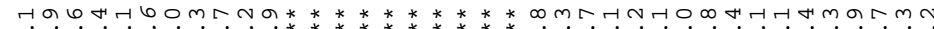
400்

안

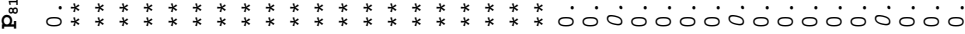

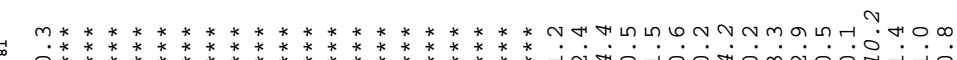

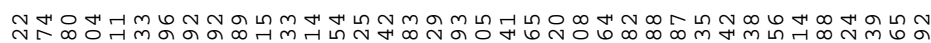

य

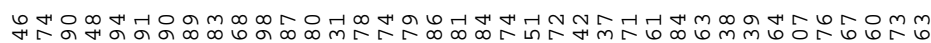

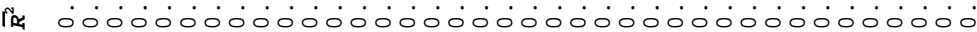

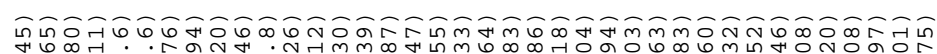

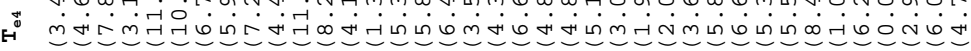

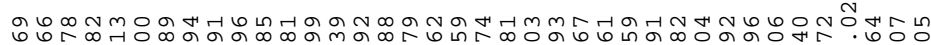

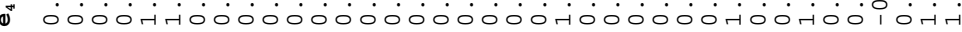

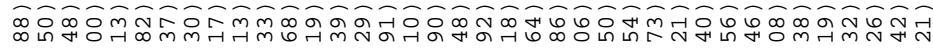
н อง

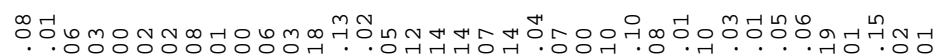

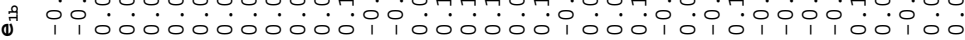

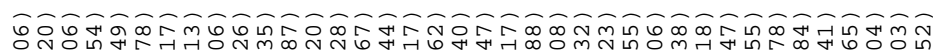

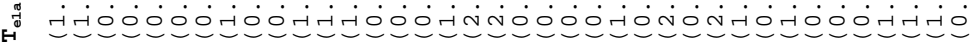

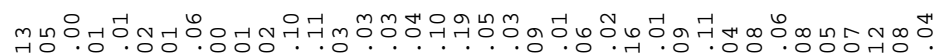

ه o.

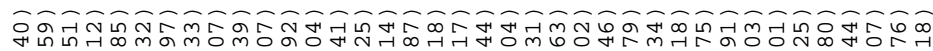

๓

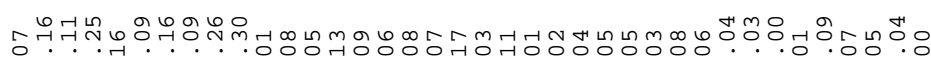

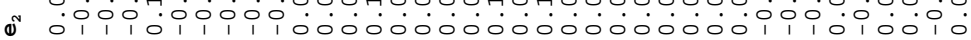

नำㅇำ

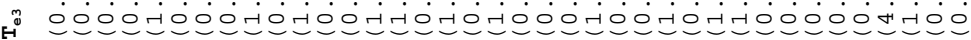

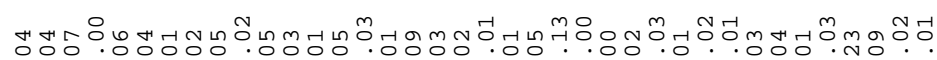

"

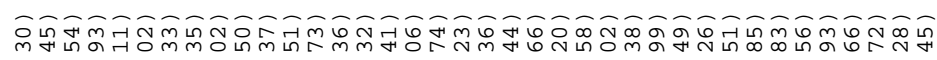

њ อ

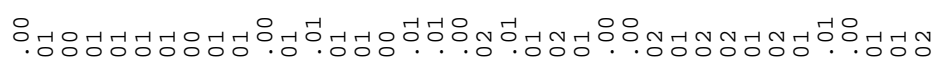

-

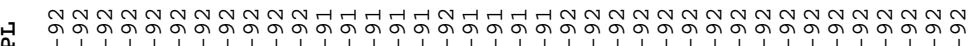

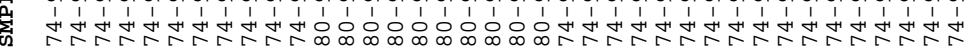

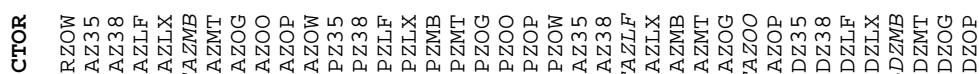

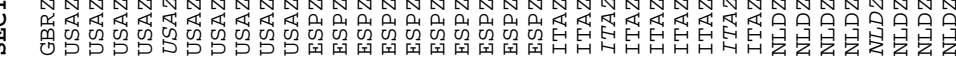




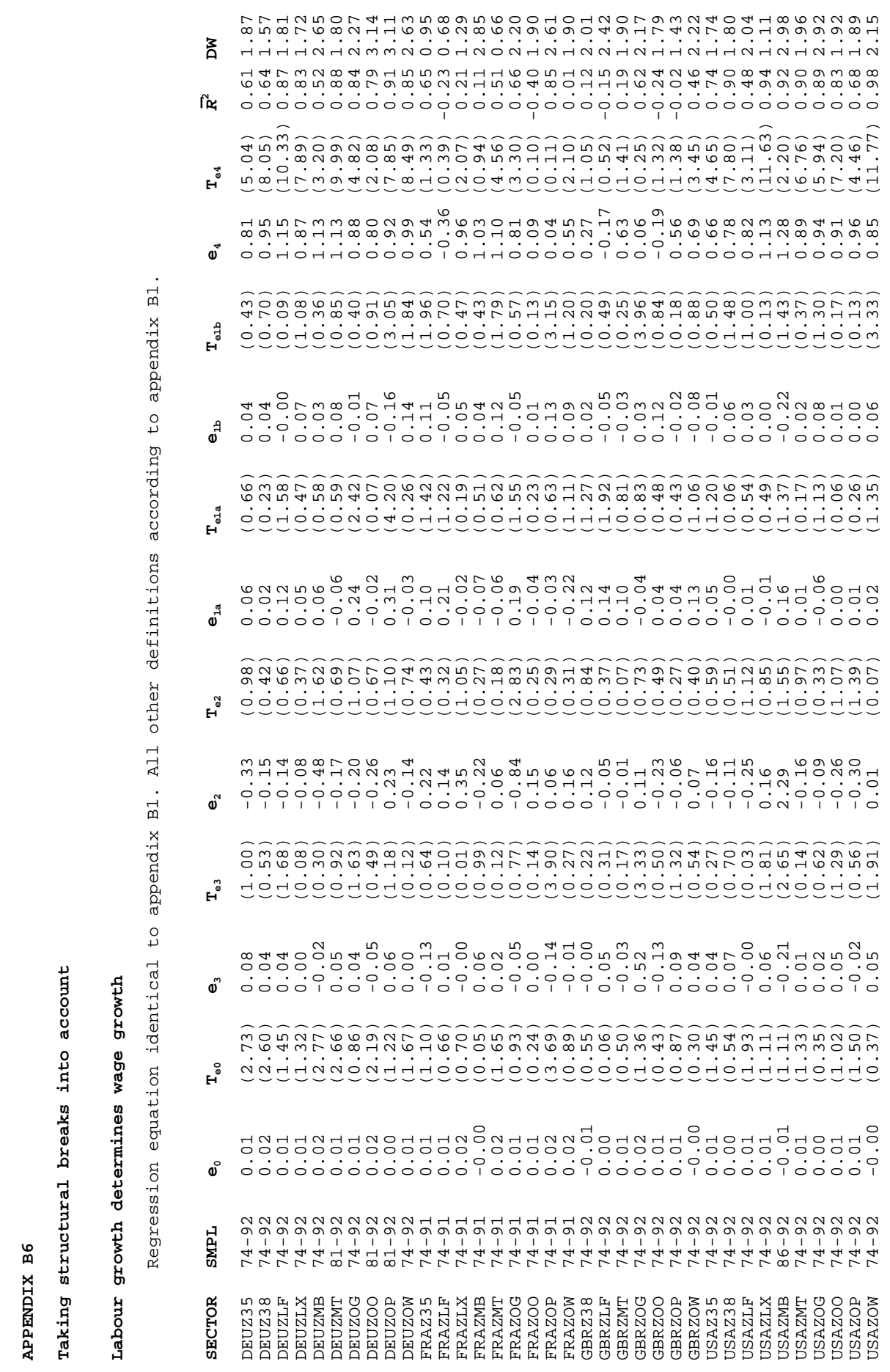




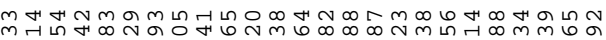

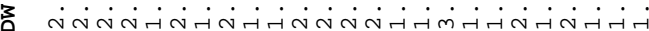

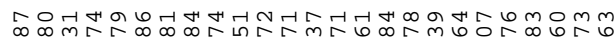

IR 0000000000000000000

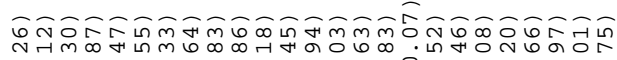

ث

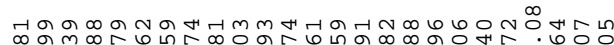

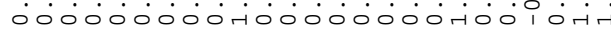

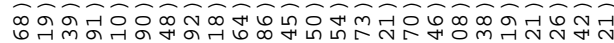

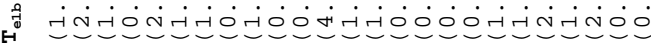

a

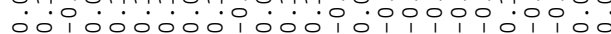

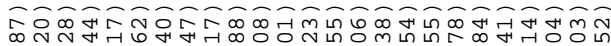

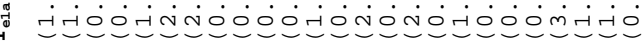

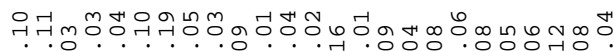

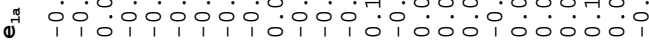

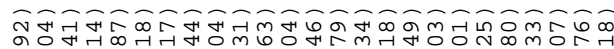
क

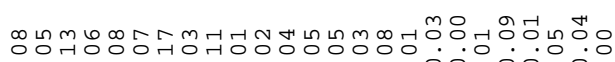
"

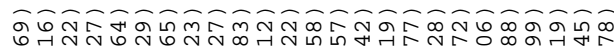

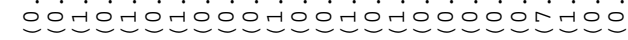
๓ว o

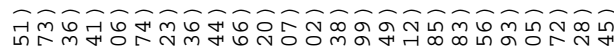

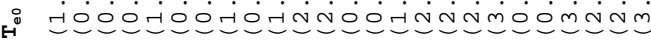

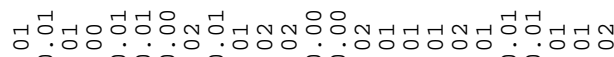

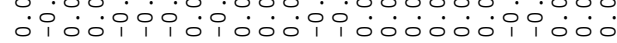

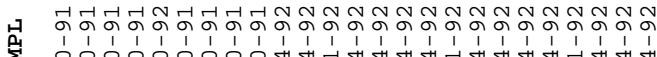

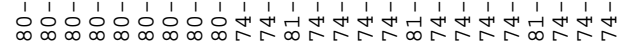

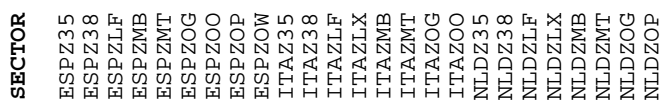

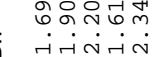

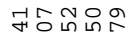

IR

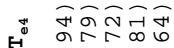

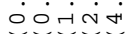

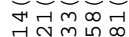

\& 0.000

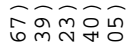
Fै $\dot{0} \dot{0} \dot{0} \dot{0}$

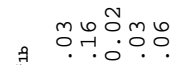

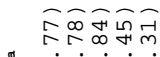

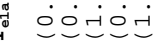

ه $\checkmark$ ㅎํำ

คै

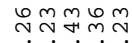

0 क人ิน

$H^{m}$ تं mm.n.

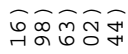

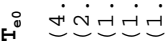
mam-ñ - i i i i

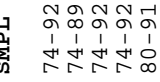

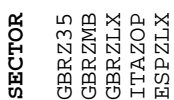




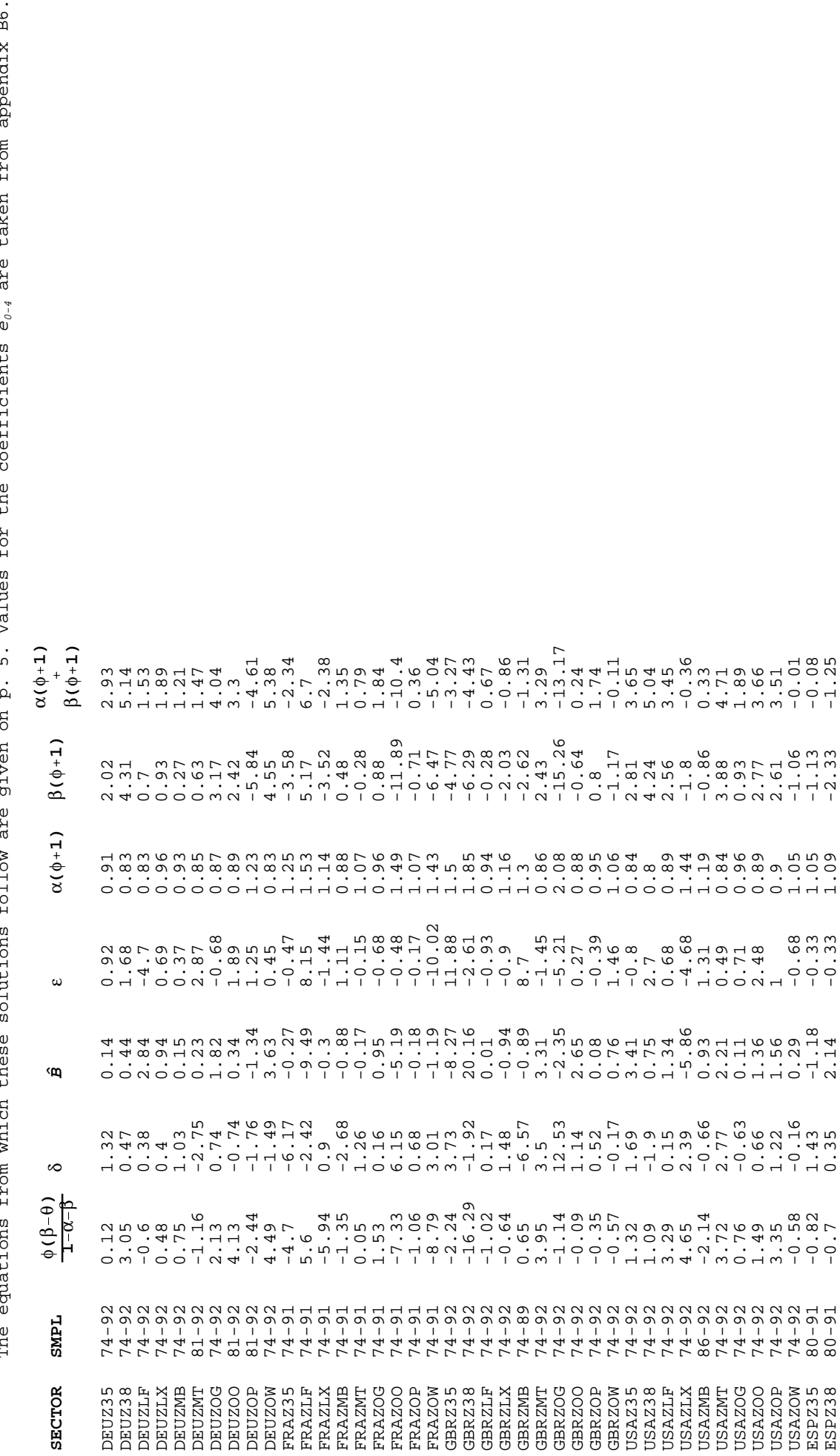




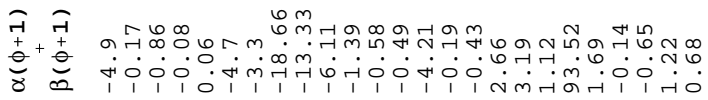

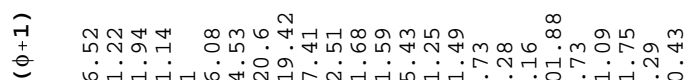

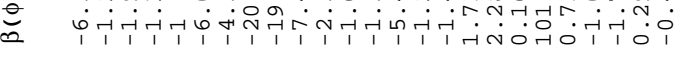

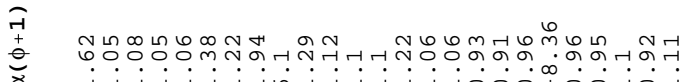

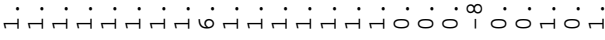

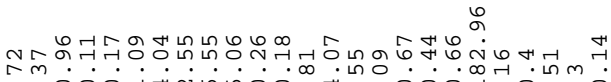

w Noi

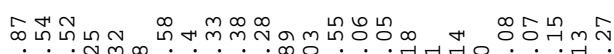

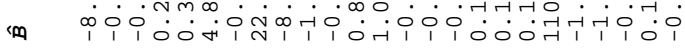

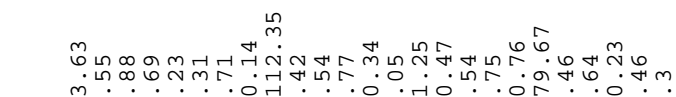

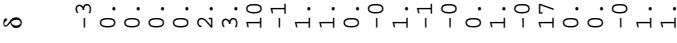

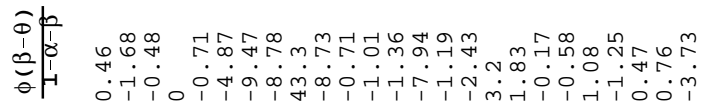

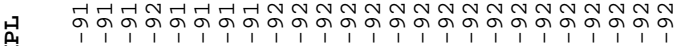

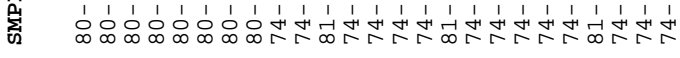

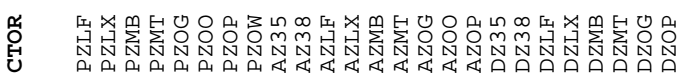

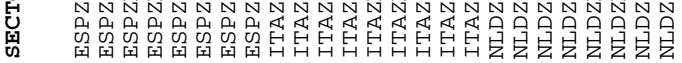

